\title{
Vibration Analysis and Modeling of an Off-Road Vibratory Roller Equipped with Three Different Cab's Isolation Mounts
}

\author{
Vanliem Nguyen $\mathbb{D}^{1,2}$ Jianrun Zhang $\mathbb{D}^{1},{ }^{1}$ Vanquynh Le, ${ }^{2}$ and Renqiang Jiao ${ }^{3}$ \\ ${ }^{1}$ School of Mechanical Engineering, Southeast University, Nanjing, China \\ ${ }^{2}$ Faculty of Automotive and Power Machinery Engineering, Thai Nguyen University of Technology, Thai Nguyen, Vietnam \\ ${ }^{3}$ School of Mechanical and Electrical Engineering, Hubei Polytechnic University, Huangshi, China
}

Correspondence should be addressed to Jianrun Zhang; zhangjr@seu.edu.cn

Received 12 December 2017; Revised 9 March 2018; Accepted 28 March 2018; Published 15 May 2018

Academic Editor: Edoardo Sabbioni

Copyright (C) 2018 Vanliem Nguyen et al. This is an open access article distributed under the Creative Commons Attribution License, which permits unrestricted use, distribution, and reproduction in any medium, provided the original work is properly cited.

This study proposes a dynamic model of the vibratory roller interacting with the off-road deformed terrain to analyze the lowfrequency performance of three different cab's isolation mounts under the different operating conditions. In order to evaluate the ride comfort of the vibratory roller with the different cab's isolation mounts, a three-dimensional nonlinear dynamic model is established. The power spectral density (PSD) and the weighted root mean square (RMS) of acceleration responses of the vertical driver's seat, cab's pitch, and roll vibrations are chosen as objective functions in the low-frequency range. Contrastive analysis of low-frequency vibration characteristics of the vibratory roller with the traditional rubber mounts, the hydraulic mounts, and the pneumatic mounts is carried out. Experimental investigations are also used to verify the accuracy of models. The research results show that the hydraulic mounts have an obvious effect on mitigating the cab vibration and improving the ride comfort in comparison with the traditional rubber mounts and the pneumatic mounts.

\section{Introduction}

The vibratory roller is a type of the soil compactor which is mainly used in the field of the construction project on roads, railways, airports, and so on. There is a combination of the static force of the vehicle and the dynamic force of the vibratory drum yielded by an eccentric mass rotating around the drum axis to compact soil, asphalt, and other materials in its work process [1-3]. Therefore, the vibration dynamics of the vehicle are generated from two main sources: One is the wheels interacting the deformable terrain when the vehicle travels and the other is interactions between the drum/tyres and the elastoplastic terrain when the vehicle compacts the soil ground $[3,4]$. Basic researches of the tyre-soft soil interaction models, which were proposed by Bekker and Wong $[5,6]$, had been applied for researching the effect of soil deformation on off-road vehicle ride responses $[4,7,8]$. Besides, based on the theoretical approach of $\mathrm{AS}^{2} \mathrm{TM}$, a model of elastic tyre-soil interaction was proposed to investigate the tyre dynamic behaviours on various soil deformations [9]. The dynamic pressure-sinkage relationship of a smooth rigid wheel-terrain interaction model was also studied from the literature and experimental observations [10]. In addition, the effect of the rough terrain surfaces and various off-road terrains had been researched for wheelssoil contact model of earth-moving machinery $[8,11,12]$. All the above results indicated that the vibration responses of interactive models are greatly influenced by deformable soil ground.

The traditional interactive models between the drum and elastoplastic soil ground were carried out by Adam and Kopf, and Rinehart and Mooney $[2,13]$ to study the deformable properties of elastic-plastic soil ground in the actual operation conditions. Besides, the excitation force of the drum on the soil grounds was also controlled to enhance the performance of the compaction process [3]. The simulation and experiment methods of the vibratory roller-terrain interaction model with the optimal parameters of the wheels, the drum isolation mounts, and the drum mass were then examined by Li et al. [14]. However, all the above researches 
almost focus on exploring the soil compression efficiency with wheels-terrain interaction models. Ride dynamics of the vibratory roller received only a little attention.

The low-frequency excitation arising from the wheelsterrain interaction is mostly transmitted to the driver via cab's isolation mounts and seat's suspension. Furthermore, vibrations in the low-frequency range of $0.5-10 \mathrm{~Hz}$ caused by terrain roughness can lead to the main risk factors which seriously affect the driver's mental and physical health [15, 16]. Consequently, cab's isolation mounts are one of the most important factors to improve the driver's ride comfort. The isolation mounts used for the vibratory roller cab are mostly equipped with the traditional rubber mounts with their stiffness and damping constants $[3,13,14]$. The influence of the design parameters of the cab rubber mounts on the ride dynamics of the soil compactor was investigated via the analytical and experimental methods [12], and their parameters were then optimized to enhance the driver's ride comfort [17]; however, the vertical driver's seat and cab's pitch vibrations are still great under operation conditions. Consequently, the traditional rubber mounts of the cab are difficult to satisfy the driver's ride comfort.

Nowadays, the cab's isolation mounts of construction equipment, industrial vehicle, and earth-moving machinery are being replaced by the increasing use of the hydraulic mounts to improve the ride comfort [18-20]. A six-degreeof-freedom (DOF) cab model of earth-moving machinery with the hydraulic mounts involving quadratic damping was also investigated under the road roughness excitation within a frequency range below $10 \mathrm{~Hz}$ [21]. The results showed that the root mean square (RMS) of acceleration responses and the power spectral density (PSD) of displacement responses of the cab's mass centre are all reduced remarkably with the comparison between hydraulic and rubber mounts. Although the paper has not yet considered the influence of wheelsterrain interactions, however, the research results are an obvious basis for study and application of the hydraulic mounts into cab's isolation mounts of machines working on deformable soil grounds, especially the soil compactors.

Besides, the pneumatic suspension systems, which were used in the suspension systems of the car, heavy truck, and rail vehicles to improve the ride dynamics and noise levels [22-24], were also investigated and applied for cab's isolation mounts and the driver's seat suspension to enhance the ride comfort as well as the driver's health and safety [25-27]. The research results showed that the vehicle ride comfort was obviously improved by using the pneumatic suspension systems. Moreover, the theory studies also showed that the pneumatic mounts used in vibration isolation mounts can result in their stiffness being almost 10 times higher than the lowest stiffness at approximately $8 \mathrm{~Hz}$ [28]; thus, this leads to the application in a low-frequency range of vibration isolation systems being necessary. Air springs have not only lower resonance frequencies but also smaller overall length than mechanical springs with equivalent properties [23]. However, the pneumatic mounts have not yet been studied to apply on cab's isolation mounts of the off-road vehicles, especially the vibratory roller.
In this study, a three-dimensional nonlinear dynamic model of a single drum vibratory roller was established based on Adam and Kopf's elastic-plastic soil model [2] and Bekker hypothesis of the soft soil ground [5]. The vibration excitations consisted of the interactions of the drum/wheelsterrain roughness surface when the vehicle travelled on a soft soil ground and a low/high excitation frequency $28 / 35 \mathrm{~Hz}$ of the drum when the vehicle compacted an elastoplastic soil ground. Experimental investigations were used to validate the models and verify their accuracy. Three different cab's isolation mounts including the traditional rubber mounts, the hydraulic mounts, and the pneumatic mounts were, respectively, simulated. The performance of three different isolation mounts was then evaluated through the acceleration PSD and the weighted RMS acceleration responses of the vertical driver's seat, cab's pitch, and roll vibrations in both the frequency and time domains.

The innovation in this paper is that an 11-DOF vehicle dynamics model which can fully reflect the pitch and roll vibrations of the cab is established. The vibration responses of the vibratory roller under the low excitation frequency, especially the pitch and roll response of cab with three different isolation mounts, are compared and analyzed. The results showed that the low-frequency and high-stiffness characteristics of the hydraulic mounts have a good effect on isolating low-frequency vibration transmitted and controlling the cab shaking of the vibratory roller.

\section{Materials and Methods}

2.1. The Vibratory Roller Dynamic Model. As shown in Figure 1(a), the basic structure of the vibratory roller consists of the rigid drum/wheels, the front/rear vehicle frame, the $\mathrm{cab}$, and the seat. Moreover, the drum and the front frame are connected by the rubber mounts, and the front frame and the rear frame are linked by an articulation connection. The cab is connected with the rear frame via the cab's isolation mounts which contains the traditional rubber mounts, the hydraulic mounts, and the pneumatic mounts as shown in Figures 1(b), $1(\mathrm{c})$, and $1(\mathrm{~d})$, respectively. In this study, three different cab's isolation mounts are used for analyzing the low-frequency performance of the vibratory roller considering the interaction between wheels and off-road deformable terrain.

A three-dimensional nonlinear dynamic model with 11 DOF of a single drum vibratory roller considering the interaction between the drum/wheels and the deformable terrain is built as in Figure 2.

See Figure 2, where $z_{s}$ is the vertical motion at the driver's seat, $z_{c}, \phi_{c}$, and $\theta_{c}$ are the vertical, the pitch, and the roll motions at the cab, respectively, and those are described as $z_{\mathrm{rf}}, \phi_{\mathrm{rf}}$, and $\theta_{\mathrm{rf}}$ at the rear vehicle frame. The vertical and roll motions of the front frame and the drum are described as $z_{\mathrm{ff}}$, $\theta_{\mathrm{ff}}$, and $z_{d}, \theta_{d}$. The mass of the driver's seat, the cab, the front frame, the engine and the rear frame, and the roller drum is described as $m_{s}, m_{c}, m_{\mathrm{ff}}, m_{\mathrm{rf}}$, and $m_{d}$, respectively. $l_{u}$ and $b_{v}$ are the longitudinal and lateral distances of the seat, the cab, and the vehicle $(u=1-8 ; v=1-7) . q_{t j}$ and $q_{d j}$ are the terrain roughness surface at wheels and drum contacts. The driver's seat suspension, drum mounts, and tyres are characterized 


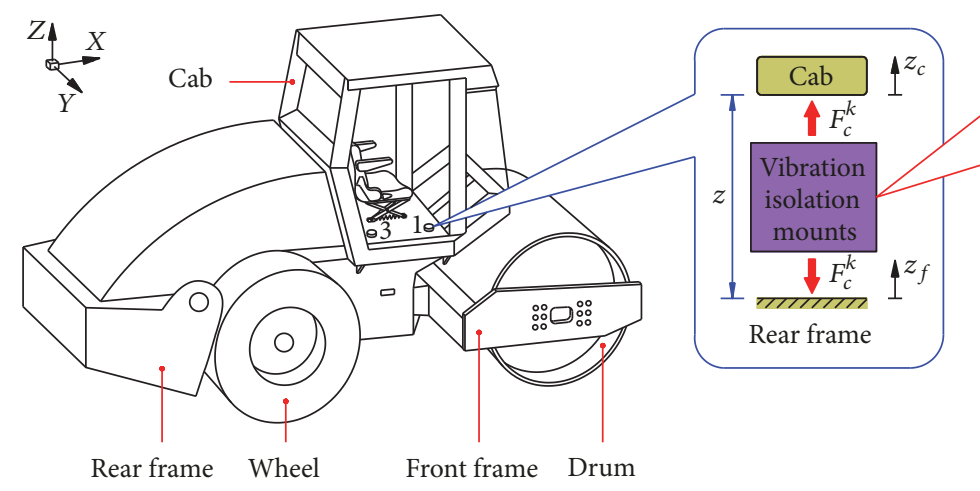

(a) Single drum vibratory roller

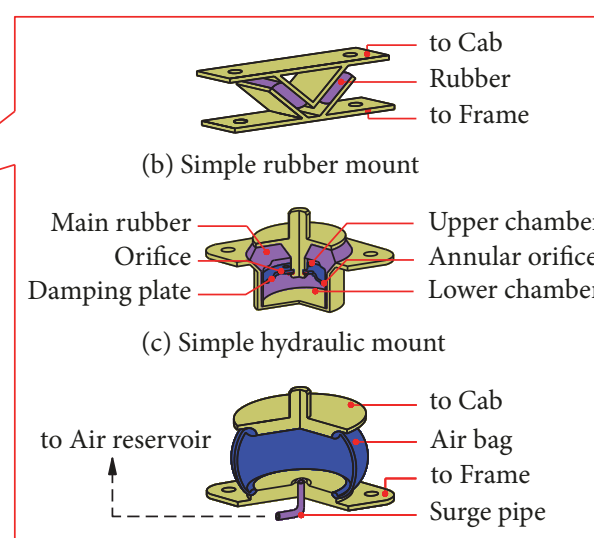

(d) Simple pneumatic mount

FIGURE 1: Schematic of vibratory roller with three different cab's isolation mounts.

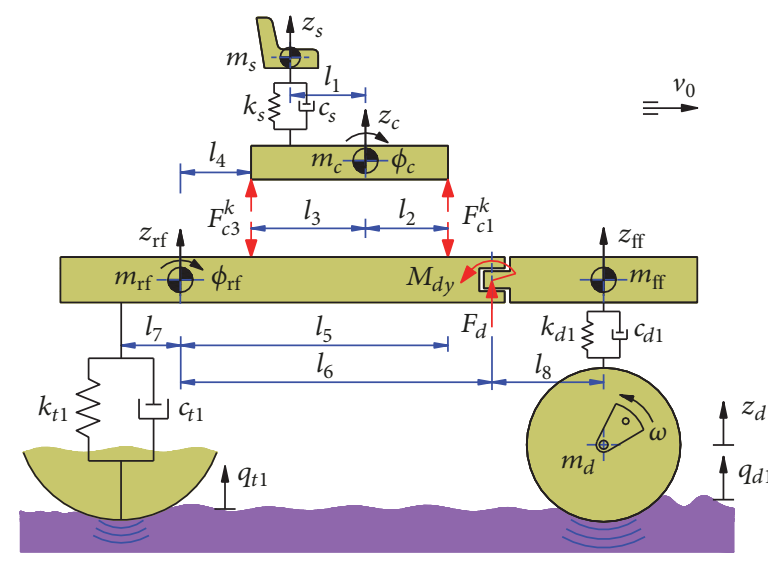

(a) Side view

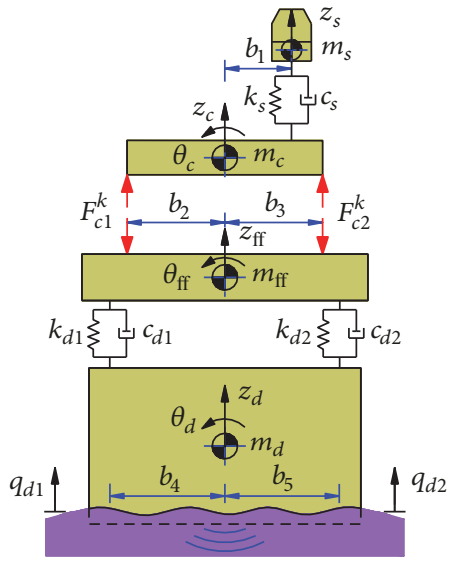

(b) Front view

FIGURE 2: Lumped-parameter model.

by the linear stiffness coefficients $k_{s}, k_{d j}, k_{t j}$ and the linear damping coefficients $c_{s}, c_{d j}, c_{t j}$, respectively $(j=1-2) . v_{0}$ is the vehicle forward speed.

The vertical dynamic forces generated by the cab's isolation mounts are described by $F_{c i}^{k}$. Herein, superscript $k$ denotes $\mathrm{R}, \mathrm{H}$, or $\mathrm{P}$ which is the abbreviation of traditional rubber mounts, hydraulic mounts, or pneumatic mounts, respectively $(i=1-4)$.

The vertical dynamic force of the driver's seat suspension is described by

$$
\begin{aligned}
F_{s}= & k_{s}\left(z_{s}-z_{c}-l_{1} \phi_{c}-b_{1} \theta_{c}\right) \\
& +c_{s}\left(\dot{z}_{s}-\dot{z}_{c}-l_{1} \dot{\phi}_{c}-b_{1} \dot{\theta}_{c}\right) .
\end{aligned}
$$

Moreover, the vertical dynamic forces $F_{d j}$ at the articulated-frame steered can be described by the vertical force $F_{d}$, the rotation moment of pitch axis $M_{d y}$, and the rotation moment of roll axis $M_{d x}$ as follows:

$$
\begin{aligned}
F_{d} & =F_{d 1}+F_{d 2}, \\
M_{d y} & =\left(F_{d 1}+F_{d 2}\right) l_{8}, \\
M_{d x} & =F_{d 1} b_{4}+F_{d 2} b_{5} .
\end{aligned}
$$

On the basis of Newton's second law of motion, the motion equations of the driver's seat, cab, and front/rear frame can be written as follows:

$$
\begin{aligned}
& m_{s} \ddot{z}_{s}=-F_{s}, \\
& m_{c} \ddot{z}_{c}=F_{s}-\left(F_{c 1}^{k}+F_{c 2}^{k}+F_{c 3}^{k}+F_{c 4}^{k}\right), \\
& I_{c y} \ddot{\phi}_{c}=F_{s} l_{1}+\left(F_{c 1}^{k}+F_{c 2}^{k}\right) l_{2}-\left(F_{c 3}^{k}+F_{c 4}^{k}\right) l_{3}, \\
& I_{c x} \ddot{\theta}_{c}=F_{s} b_{1}+\left(F_{c 1}^{k}+F_{c 3}^{k}\right) b_{2}-\left(F_{c 2}^{k}+F_{c 4}^{k}\right) b_{3},
\end{aligned}
$$




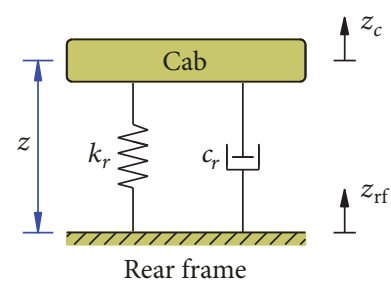

(a) Traditional rubber mount

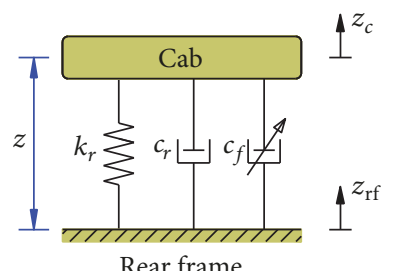

(b) Hydraulic mount

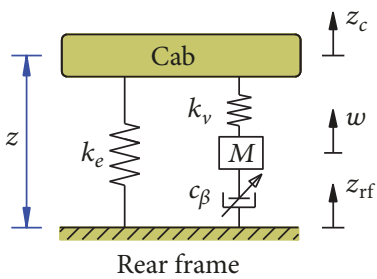

(c) Pneumatic mount

FIGURE 3: Lumped-parameter models of three cab's isolation mounts.

$$
\begin{aligned}
m_{\mathrm{rf}} \ddot{z}_{\mathrm{rf}}= & \left(F_{c 1}^{k}+F_{c 2}^{k}+F_{c 3}^{k}+F_{c 4}^{k}\right)-\left(F_{d}+F_{t 1}+F_{t 2}\right), \\
I_{\mathrm{rf} y} \ddot{\phi}_{\mathrm{rf}}= & \left(F_{c 3}^{k}+F_{c 4}^{k}\right) l_{4}-\left(F_{c 1}^{k}+F_{c 2}^{k}\right) l_{5}+F_{d} l_{6} \\
& -\left(F_{t 1}+F_{t 2}\right) l_{7}+M_{d y}, \\
I_{\mathrm{rf} x} \ddot{\theta}_{\mathrm{rf}}= & \left(F_{c 2}^{k}+F_{c 4}^{k}\right) b_{3}-\left(F_{c 1}^{k}+F_{c 3}^{k}\right) b_{2}+F_{t 1} b_{6}-F_{t 2} b_{7} \\
& -M_{d x}, \\
m_{\mathrm{ff}} \ddot{z}_{\mathrm{ff}}= & F_{d 1}+F_{d 2}, \\
I_{\mathrm{ff} x} \ddot{\theta}_{\mathrm{ff}}= & F_{d 1} b_{4}-F_{d 2} b_{5} .
\end{aligned}
$$

The system of the above differential equations can be represented in the matrix form as follows:

$$
[\mathbf{M}]\{\ddot{\mathbf{Z}}\}+[\mathbf{C}]\{\dot{\mathbf{Z}}\}+[\mathbf{K}]\{\mathbf{Z}\}=\{\mathbf{F}(t)\},
$$

where $[\mathbf{M}],[\mathbf{C}]$, and $[\mathbf{K}]$ are $(m \times m)$ mass, damping, and stiffness matrices, respectively, $\{\mathbf{Z}\}$ is the $(m \times 1)$ displacement vector, $\{\mathbf{F}(t)\}$ is the $(m \times 1)$ exciting force vector, and $m$ is the number of DOF $(m=9)$.

\subsection{Modeling of Three Cab's Isolation Mounts}

2.2.1. Mathematic Model of the Traditional Rubber Mounts. The traditional rubber mounts are widely used for cab's isolation mounts of the vibratory roller to reduce the vibrations. The viscoelastic properties of the traditional rubber mount are mainly modeled by a linear stiffness $k_{r}$ and damping coefficient $c_{r}$, as shown in Figure 3(a). The corresponding dynamic force of the mount $i$ of rubber mounts in the vertical direction can be written as follows:

$$
\begin{aligned}
& F_{c i}^{R}=k_{r i}\left(z_{c i}-z_{\mathrm{rfi} i}\right)+c_{r i}\left(\dot{z}_{c i}-\dot{z}_{\mathrm{rf} i}\right), \\
& z_{c i}=z_{c}+(-1)^{\alpha} l_{\alpha+1} \phi_{c}+(-1)^{i} b_{\delta} \theta_{c}, \\
& z_{\mathrm{rf} i}=z_{\mathrm{rf}}-l_{v} \phi_{\mathrm{rf}}+(-1)^{i} b_{\delta} \theta_{\mathrm{rf}}, \\
& \dot{z}_{c i}=\dot{z}_{c}+(-1)^{\alpha} l_{\alpha+1} \dot{\phi}_{c}+(-1)^{i} b_{\delta} \dot{\theta}_{c}, \\
& \dot{z}_{\mathrm{rf} i}=\dot{z}_{\mathrm{rf}}-l_{v} \dot{\phi}_{\mathrm{rf}}+(-1)^{i} b_{\delta} \dot{\theta}_{\mathrm{rf}},
\end{aligned}
$$

where $z_{c i}, z_{\mathrm{rf} i}$ and $\dot{z}_{c i}, \dot{z}_{\mathrm{rfi} i}$ are the displacements and the velocities of the cab floor and the rear frame at mount $i$ of the isolation mounts; when $i=1-2$ then $\alpha=1, v=5$, and $\delta=i+1$; when $i=3-4$ then $\alpha=2, v=4$, and $\delta=i-1$.

2.2.2. Mathematic Model of the Hydraulic Mounts. It is shown in Figure 1(c) that the hydraulic mount consists of the main rubber, a damping plate driven by the bolt, and a closed chamber filled with the fluid. The fluid flow in the upper-lower chamber is derived by the transfer of damping plate through the annular orifice and the orifices. Assuming the inertial forces in the annular orifice and the orifices are very small, their values can be neglected. The dynamic behaviour of the fluid flow through the annular orifice and the orifices is mainly in the vertical direction $z$. Thus, the unequal pressure between two chambers $\Delta p$ can be computed by the sum of the pressure losses through the annular orifice $\left(\Delta p_{a}=c_{a}\left|\dot{z}_{a}\right| \dot{z}_{a}\right)$ [20] and the orifices $\left(\Delta p_{o}=c_{o}\left|\dot{z}_{o}\right| \dot{z}_{o}\right)$ [29] as follows:

$$
\Delta p=\Delta p_{a}+\Delta p_{o}=c_{a}\left|\dot{z}_{a}\right| \dot{z}_{a}+c_{o}\left|\dot{z}_{o}\right| \dot{z}_{o},
$$

where $\dot{z}_{a}$ and $\dot{z}_{o}$ are the average flow velocities in the annular orifice and the orifices and $c_{a}$ and $c_{o}$ are the constants determined by the geometric dimensions of the annular orifice and the orifices, respectively.

The flow $Q_{c}$ in the closed chamber through the annular orifice and the orifices is described by the equations of continuity

$$
\begin{aligned}
Q_{c} & =A_{c} \dot{z}=A_{a} \dot{z}_{a}, \\
\text { or } Q_{c} & =A_{c} \dot{z}=A_{o} \dot{z}_{o},
\end{aligned}
$$

where $A_{c}, A_{a}$, and $A_{o}$ are the effects of the chamber, annular orifice, and orifices area, respectively, and $\dot{z}$ is the relative velocity between the cab floor and the rear frame.

Equation (8), thus, can be computed by $\dot{z}$ as follows:

$$
\Delta p=\left[c_{a}\left(\frac{A_{c}}{A_{a}}\right)^{2}+c_{o}\left(\frac{A_{c}}{A_{o}}\right)^{2}\right]|\dot{z}| \dot{z} .
$$

With effect of the damping plate area $A_{d}$ and the unequal pressure between two chambers $\Delta p$, the liquid damping force $f$ is derived by

$$
f=A_{d} \Delta p=c_{f}|\dot{z}| \dot{z},
$$

where $c_{f}=A_{d}\left[c_{a}\left(A_{c} / A_{a}\right)^{2}+c_{o}\left(A_{c} / A_{o}\right)^{2}\right]$ is the damping constant. 
Therefore, the hydraulic mount applied for cab's isolation mounts can be modeled by the lumped-parameter model shown in Figure 3(b). The corresponding dynamic force of the mount $i$ of hydraulic mounts in the vertical direction is described by

$$
\begin{aligned}
F_{c i}^{\mathrm{H}}= & k_{r i}\left(z_{c i}-z_{\mathrm{rfi}}\right)+c_{r i}\left(\dot{z}_{c i}-\dot{z}_{\mathrm{rfi} i}\right) \\
& +c_{f i}\left|\dot{z}_{c i}-\dot{z}_{\mathrm{rfi} i}\right|\left(\dot{z}_{c i}-\dot{z}_{\mathrm{rfi} i}\right),
\end{aligned}
$$

where $z_{c i}, z_{\mathrm{rf} i}$ and $\dot{z}_{c i}, \dot{z}_{\mathrm{rf} i}$ are derived in (6) and (7).

2.2.3. Mathematic Model of the Pneumatic Mounts. The pneumatic mount includes an air bag that is connected to an air reservoir via a surge pipe system. The structure of a simple pneumatic mount is shown in Figure $1(\mathrm{~d})$. The mechanical behaviour, mainly based on fluid dynamic and thermodynamic mechanisms, is often very complicated, which is determined by the characteristic parameters of the pressure, temperature, volume, mass, density, and energy of the air as well as the shape of the air bag.

According to the method of calculation of a simple pneumatic mount in [22], assume that air bag is deflected in the vertical direction $z$. After the deflection, the new air bag volume $V_{b}$ and the new reservoir volume $V_{r}$ with the polytropic process are

$$
\begin{aligned}
& V_{b}=V_{b 0}-A_{e} z+A_{s} w, \\
& V_{r}=V_{r 0}-A_{s} w,
\end{aligned}
$$

where $V_{b 0}$ and $V_{r 0}$ are the initial volumes of the air bag and the reservoir, $A_{e}$ is the effective area of air bag, $A_{s}$ is the crosssection area of the pipeline, and $w$ is the displacement of air in surge pipe.

The GENSYS model of the pneumatic mount, as illustrated in Figure 3(c), has polytropic gas state change. For this model, the static and viscous stiffness constants $k_{e}$ and $k_{v}$ and the mass $M$ can be, respectively, written by [23]

$$
\begin{aligned}
& k_{e}=\frac{p_{0} A_{e}^{2} \lambda}{V_{b 0}+V_{r 0}}, \\
& k_{v}=k_{e} \frac{V_{r 0}}{V_{b 0}}, \\
& M=A_{s} l_{s} \rho\left(\frac{A_{e}}{A_{s}} \frac{V_{r 0}}{V_{b 0}+V_{r 0}}\right)^{2},
\end{aligned}
$$

where $\lambda$ is the polytropic rate $(1<\lambda<1.4), p_{0}$ is the initial pressure in the air bag, $l_{s}$ is the length of the surge pipe, and $\rho$ is the air density.

The nonlinear viscous damper $c_{\beta}$ is only related to the velocity over the damper $\left(c_{\beta}\right)$, and the vertical viscous force $F_{v z}$ is expressed by [30]

$$
\begin{aligned}
F_{v z} & =k_{v}(z-w)=c_{\beta}|\dot{w}|^{\beta} \operatorname{sign}(\dot{w})+M \ddot{w}, \\
M \ddot{w} & =k_{v}(z-w)-c_{\beta}|\dot{w}|^{\beta} \operatorname{sign}(\dot{w}) .
\end{aligned}
$$

The relationship between the nonlinear damping $c_{\beta}$ and the damping $c_{s}$ is described by

$$
c_{\beta}=c_{s}\left(\frac{A_{e}}{A_{s}} \frac{V_{r 0}}{V_{b 0}+V_{r 0}}\right)^{1+\beta},
$$

in which $c_{s}=(1 / 2) \rho A_{s} c_{\mathrm{st}}=(1 / 2) \rho A_{s}\left(c_{\mathrm{fr}}+c_{\mathrm{en}}+c_{c}+c_{b}\right)$, where $c_{\text {st }}$ is total loss coefficient, $c_{\mathrm{fr}}$ is the loss coefficient due to friction, $c_{\mathrm{en}}$ is the loss coefficient due to enlargement, $c_{c}$ is the loss coefficient due to contraction, and $c_{b}$ is the loss coefficient due to bends in the pipe.

The dynamic force of pneumatic mount in the vertical direction can be derived by

$$
F_{c}^{P}=k_{e} z+k_{v}(z-w) .
$$

By combining (15) and (17), the corresponding dynamic force of the mount $i$ of pneumatic mounts in the vertical direction can be written as follows:

$$
\begin{aligned}
M_{i} \ddot{w}_{i} & =k_{v i}\left(z_{c i}-z_{\mathrm{rf} i}-w_{i}\right)-c_{\beta i}\left|\dot{w}_{i}\right|^{\beta_{i}} \operatorname{sign}\left(\dot{w}_{i}\right), \\
F_{c i}^{\mathrm{P}} & =k_{e i}\left(z_{c i}-z_{\mathrm{rf} i}\right)+k_{v i}\left(z_{c i}-z_{\mathrm{rf} i}-w_{i}\right),
\end{aligned}
$$

where $z_{c i}$ and $z_{\mathrm{rfi}}$ are also derived in (6) and (7).

2.3. Dynamic Off-Road Vehicle and Deformable Soil Interaction Models. In actual operation conditions, the drum and wheels often interact with the deformable soil grounds. Therefore, a rigid drum- and the elastic tyres-deformable soil contact when the vehicle travels on the soft terrain and a rigid drum-elastoplastic soil interaction when the vehicle compacts the elastoplastic soil ground are given to establish the interactional models.

2.3.1. The Rigid Drum-Deformable Soil Contact Model. The ride vibration responses of vehicles are greatly influenced by the rough terrain surfaces apart from the operating factors and various designs. Accordingly, the random excitation on various off-road terrains of the wheel-soft terrain contact model [6], of the elastic tyre-soft terrain contact model [11], and of the rigid drum-elastic soil interaction model [17] is concerned to evaluate the vehicle ride vibration, respectively.

In this study, a single rigid drum-deformable soil contact model with the terrain roughness surface is investigated based on the traditional model of Bekker and Wong $[5,6]$. When the drum traverses on a random terrain surface $q(t)$ of a deformable terrain, under the effect of the static and dynamic loads of the drum, the terrain is then sunk $z_{o a}$, as shown in Figure 4(a). The pressure $p_{g}$ and the shear stress $\tau_{g}$ arising from the soil compression in the deformable area region ( $\operatorname{arc}$ of $o a$ ) thus impact contrarily the drum. Consequently, the vertical reaction force $F_{g}$ of the soil under the drum is given by

$$
\begin{aligned}
F_{g} & =\int_{0}^{\theta_{a}(t)} B_{d} p_{g} r_{d} \cos \theta d \theta+\int_{0}^{\theta_{a}(t)} B_{d} \tau_{g} r_{d} \sin \theta d \theta \\
& =\int_{0}^{l(t)} B_{d} p_{g} d x+\int_{0}^{l(t)} B_{d} \tau_{g} x\left(r_{d}^{2}-x^{2}\right)^{-1 / 2} d x,
\end{aligned}
$$




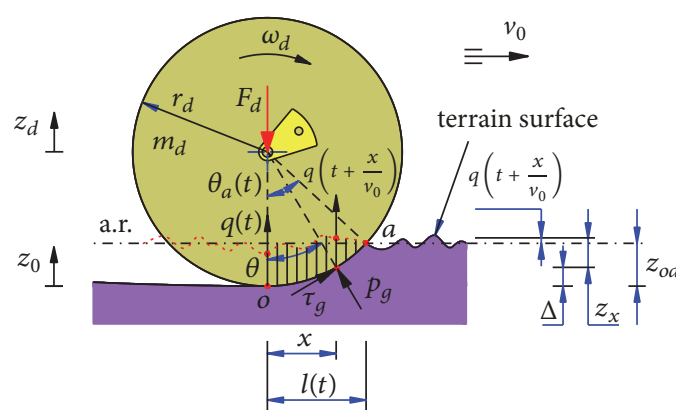

(a) The rigid drum-deformable soil

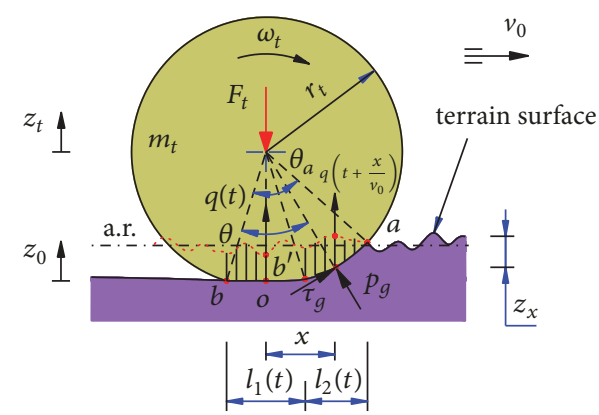

(b) The elastic tyre-deformable soil

FIGURE 4: The wheels-soil interaction models [7].

where $\theta_{a}(t)$ and $l(t)$ are the angle and length in the horizontal direction of the drum-soil contact which are generally changed and depend on the rough terrain properties.

The pressure $p_{g}$ and the shear stress $\tau_{g}$ in (19) were given by Bekker [5] as follows:

$$
\begin{aligned}
p_{g} & =\left(\frac{k_{c}}{b}+k_{\varphi}\right) z_{x}^{n}, \\
\tau_{g} & =\left(c+p_{g} \tan \varphi\right)\left(1-e^{-j_{d} / K}\right),
\end{aligned}
$$

where $k_{c}$ and $k_{\varphi}$ are the soil stiffness coefficients for sinkage and internal friction, $n$ is the sinkage exponent, $b=$ $\min \left\{B_{d}, l(t)\right\}$ is the smaller dimension of the contact patch in which $B_{d}$ is the width of the drum, $c$ is the soil cohesion coefficient, $\varphi$ is the angle of the internal friction, $j_{d}=$ $r_{d} s_{d}\left[\theta_{a}(t)-\theta\right]$ in which $s_{d}$ is the slip ratio of the drum, and $K$ is the shear deformation modulus.

Assuming a.r. is the average roughness line of the terrain surface, thus, the sinking of the soil $z_{x}$ can be determined as follows:

$$
\begin{aligned}
z_{x} & =q\left(t+\frac{x}{v_{0}}\right)+z_{o a}-\Delta \\
& =q\left(t+\frac{x}{v_{0}}\right)+z_{d}-z_{0}-\left(r_{d}-\sqrt{r_{d}^{2}-x^{2}}\right),
\end{aligned}
$$

where $r_{d}$ is the radius of the drum, $z_{0}$ is the static sinkage, $z_{d}$ is the vertical displacement of the drum centre, and $q(t+$ $\left.x / v_{0}\right)$ is the random excitation of an off-road terrain and it is described in Section 2.3.4.

The vertical excitation forces $F_{d j}$ arising due to the drum mounts are described by

$$
\begin{aligned}
F_{d j}= & k_{d j}\left[z_{\mathrm{ff}}-z_{d}+(-1)^{j} b_{j+3}\left(\theta_{\mathrm{ff}}-\theta_{d}\right)\right] \\
& +c_{d j}\left[\dot{z}_{\mathrm{ff}}-\dot{z}_{d}+(-1)^{j} b_{j+3}\left(\dot{\theta}_{\mathrm{ff}}-\dot{\theta}_{d}\right)\right] .
\end{aligned}
$$

The motion equations of the rigid drum-soft terrain contact can be written as follows:

$$
\begin{aligned}
& m_{d} \ddot{z}_{d}=F_{d 1}+F_{d 2}-F_{g}+m_{d} g, \\
& I_{d x} \ddot{\theta}_{d}=F_{d 1} b_{4}-F_{d 2} b_{5} .
\end{aligned}
$$

2.3.2. The Elastic Tyre-Deformable Soil Contact Model. When the elastic tyre traverses on the deformable terrain, under the effect of the static and dynamic loads of the wheel, the terrain is also sunk. Two deformation characteristics are presented in the tyre-soil contact region. One is the deformation between the tyre and the soil (the region of $b o b^{\prime}$ ) and the other is the unique soil (the region of $b^{\prime} a$ ), as shown in Figure 4(b). Herein, $z_{t}, z_{0}$, and $z_{x}$ are the vertical displacements of the tyre centre, the static deformation, and the sinkage of terrain, respectively. $m_{t}, \omega_{t}$, and $r_{t}$ are the mass, the angular velocity, and radius of the wheel, and $F_{t}$ is the vertical dynamic force at tyre centre.

The regions of $b o b^{\prime}$ and $b^{\prime} a$ are assumed to be a straight line $b o b^{\prime}$ with the length of contact $l_{1}(t)$ and an arc of $b^{\prime} a$ with the length of contact in the horizontal direction $l_{2}(t)$, respectively. $p_{g}$ and $\tau_{g}$ arising in the deformable regions of $b o b^{\prime}$ and $b^{\prime} a$ are described by the vertical reaction forces of terrain under the tire, $F_{g 1}^{z}$ and $F_{g 2}^{z}$ [7].

The vertical reaction force $F_{g 1}^{z}$ in the region of $b o b^{\prime}$ is calculated by

$$
F_{g 1}^{z}=F_{p_{g 1}}^{z}=2 B_{t}\left(\frac{k_{c}}{b}+k_{\varphi}\right) \int_{0}^{l_{1} / 2(t)} z_{x}^{n} d x,
$$

where $z_{x}=q\left(t+x / v_{0}\right)+z_{0}-z_{t}$ and $b=\min \left\{B_{t}, l_{1}(t)\right\}$.

The vertical reaction force $F_{g 2}^{z}$ in the region of $b^{\prime} a$ is also calculated as follows:

$$
\begin{aligned}
F_{g 2}^{z}= & F_{p_{g 2}}^{z}+F_{\tau_{g 2}}^{z} \\
= & \int_{l_{1} / 2(t)}^{l_{1} / 2(t)+l_{2}(t)} B_{t} p_{g} d x \\
& +\int_{l_{1} / 2(t)}^{l_{1} / 2(t)+l_{2}(t)} B_{t} \tau_{g} x\left(r_{t}^{2}-x^{2}\right)^{-1 / 2} d x,
\end{aligned}
$$

where the pressure $p_{g}$ and the shear stress $\tau_{g}$ are determined in $(20), b=\min \left\{B_{t}, l_{2}(t)\right\}$, and $j_{t}=r_{t} s_{t}\left[\theta_{a}(t)-\theta\right]$ in which $s_{t}$ is the slip ratio of the tyre.

The total reaction force of the terrain is given by

$$
F_{g}=F_{g 1}^{z}+F_{g 2}^{z}
$$




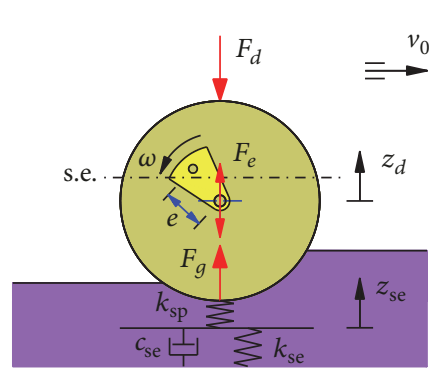

(a) Loading phase

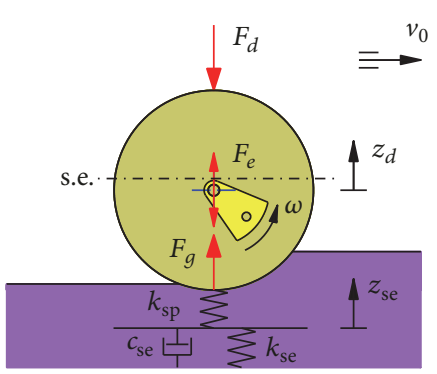

(b) Unloading phase

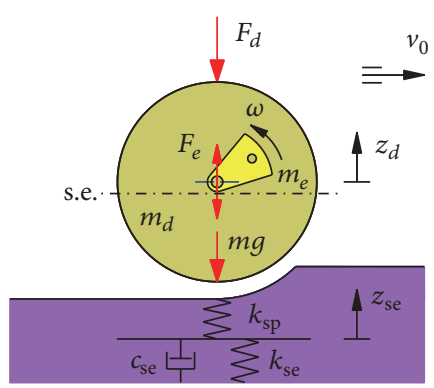

(c) Drum-hop phase

Figure 5: The rigid drum and elastoplastic soil interaction model.

The vertical excitation forces $F_{t j}$ exerted on the rear frame are described as follows:

$$
\begin{aligned}
& F_{t j}+F_{g j}-m_{t j} g=0, \\
& \begin{aligned}
F_{t j} & \\
= & k_{t j}\left[z_{\mathrm{rf}}-l_{7} \phi_{\mathrm{rf}}+(-1)^{j} b_{j+5} \theta_{\mathrm{rf}}-z_{g j}\right] \\
& +c_{t j}\left[\dot{z}_{\mathrm{rf}}-l_{7} \dot{\phi}_{\mathrm{rf}}+(-1)^{j} b_{j+5} \dot{\theta}_{\mathrm{rf}}-\dot{z}_{g j}\right],
\end{aligned}
\end{aligned}
$$

where $m_{t j}$ is the portion of total vehicle mass supported at the tyres and $g$ is the gravitational acceleration.

\subsubsection{The Rigid Drum and Elastoplastic Soil Interaction Model.} The vibration response of the drum is arising not only from the self-excitation but also from the interaction between the rigid drum and elastoplastic soil. In this study, based on the elastoplastic properties of the terrain [2], a lumped-parameter model of the drum-soil interaction in the vertical direction is built which can be divided into three phases, as shown in Figure 5.

In Figure $5, z_{d}$ and $z_{\text {se }}$ are the vertical motion of the drum and the elastic terrain deformation, $m$ is the total mass of the front frame and the drum, $m_{d}$ is the mass of the drum, $k_{\mathrm{sp}}$ and $k_{\mathrm{se}}$ are the plastic and elastic stiffness constants, $c_{\mathrm{se}}$ is the elastic damping constant, s.e. is the abbreviation of the static equilibrium, $F_{e}=m_{e} e \omega^{2} \sin \omega t$ is the vertical projection of the rotating eccentric mass $m_{e}$ in which $\omega$ is the vibrator rotational velocity, and $e$ is the eccentricity of the rotating mass. $F_{g}$ is the dynamic force yielded by the plastic deformation of the soil surface layer or the elastoplastic deformation of the soil subsequence layers which is written as follows:

$$
F_{g}=k_{\mathrm{sp}}\left(z_{d}-z_{\mathrm{se}}\right)=k_{\mathrm{se}} z_{\mathrm{se}}+c_{\mathrm{se}} \dot{z}_{\mathrm{se}}
$$

The motion equation of the drum and elastoplastic soil interaction can be described by

$$
m_{d} \ddot{z}_{d}=F_{d}-F_{g}+m_{e} e \omega^{2} \sin \omega t
$$

According to Adam and Kopf [2], the elastoplastic property can be expressed by a plasticity factor $\varepsilon$ and a soil damping to plasticity ratio $\gamma$ as follows:

$$
\begin{aligned}
& \varepsilon=\frac{k_{\mathrm{sp}}}{\left(k_{\mathrm{sp}}+k_{\mathrm{se}}\right)}, \\
& \gamma=\frac{c_{\mathrm{se}}}{k_{\mathrm{sp}}}
\end{aligned}
$$

where the mutation parameter $\varepsilon$ is from 0 to 1 . The value $\varepsilon=0$ achieved as $k_{\mathrm{sp}}=0$ refers to purely plastic soil property, which degrades the loss of the drum-soil contact. The value $\varepsilon=1$ refers to an ideal elastic soil property achieved as $k_{\text {sp }} \rightarrow$ $\infty$. Over each cycle of the vibratory drum-soil interaction, there are two or three distinct phases, which are described as follows.

(i) Loading Phase. As shown in Figure 5(a), this phase is characterized by the elastic and the plastic soil deformations. The drum moves downward while its compressive force is applied to the terrain. The necessary conditions for this phase are $F_{g}+m g>0$ and $\dot{z}_{d}>0$.

In order to describe the relation of $z_{d}, \varepsilon$, and $\gamma$, the thirdorder differential equation of the vertical roller drum-soil interaction is calculated by

$$
\begin{aligned}
\varepsilon \gamma m_{d} \ddot{z}_{d}+m_{d} \ddot{z}_{d}= & \varepsilon \gamma \dot{F}_{d}+F_{d}-\varepsilon c_{\mathrm{se}} \dot{z}_{d}+(\varepsilon-1) k_{\mathrm{sp}} z_{d} \\
& +\varepsilon \gamma m_{e} e \omega^{3} \cos \omega t+m_{e} e \omega^{2} \sin \omega t
\end{aligned}
$$

(ii) Unloading Phase. In this phase, the drum moves upward while the drum-soil contact is retained, as illustrated in Figure 5(b). The soil recovers its elastic deformation, while the plastic deformation represents the soil compaction. The plastic stiffness $k_{\mathrm{sp}}$ is thus assumed to be infinite. The necessary conditions for this phase are $F_{g}+m g>0$ and $\dot{z}_{d}<0$.

$$
m_{d} \ddot{z}_{d}=F_{d}-c_{\mathrm{se}} \dot{z}_{d}+m_{e} e \omega^{2} \sin \omega t
$$

(iii) Drum-Hop Phase. The drum continues upward motion, and the drum-soil contact is broken, as seen in Figure 5(c). 


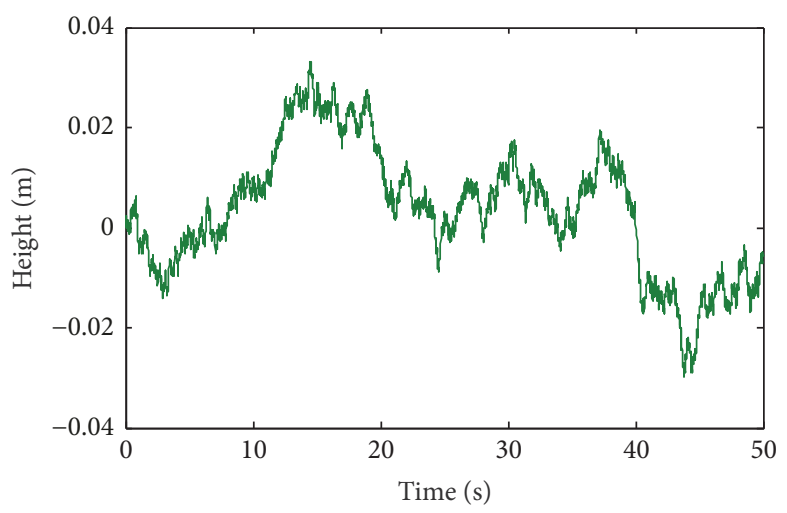

(a) The off-road terrain profile

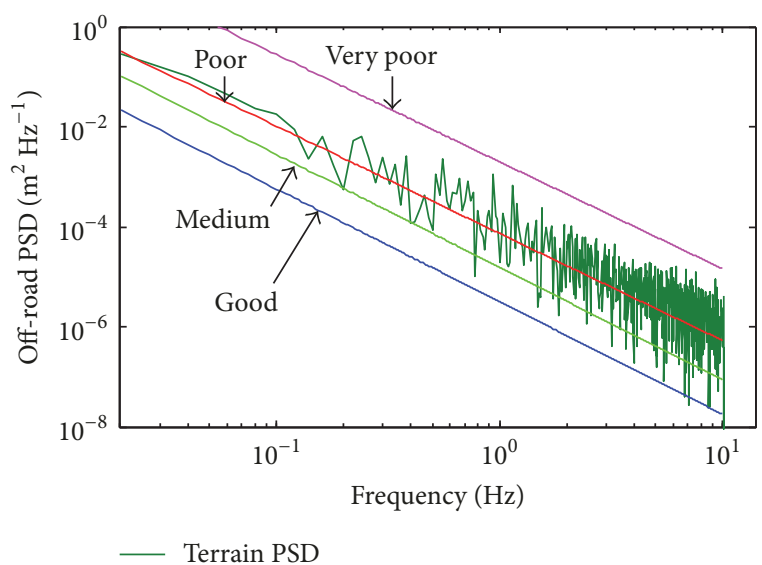

(b) Spectral densities

FIGURE 6: Generation of the off-road terrain roughness according to unpaved off-road classification.

The full elastic property of soil is thus recovered while the plastic stiffness of soil vanishes $\left(k_{\mathrm{sp}}=0\right)$, which yields $\varepsilon=0$. The necessary conditions for this phase are $F_{g}+m g=0$.

The drum-soil contact in this phase is broken and the static loads of the front frame and the drum are not balanced by any static reaction force of the terrain. The gravity component $m g$ is now considered in the motion equation of drum, rewritten by

$$
m_{d} \ddot{z}_{d}=F_{d}+m g+m_{e} e \omega^{2} \sin \omega t
$$

The motions of the drum and the elastoplastic soil interaction can be described in (31), (32), and (33). Based on the vertical motion of the drum $z_{d}$, the vertical excitation forces $F_{d}$ in (22) are then determined.

2.3.4. The Random Excitation of the Off-Road Terrain. The vehicle ride comfort is strongly influenced not only by the vibratory drum and the terrain deformation but also by the rough terrain surfaces. The terrain behaviour under wheel-soil contact is nonlinear. Thus, the off-road vehicles must be performed in the frequency domain apart from the traditional time domain to analyze the ride comfort. Off-road terrain surface in the frequency domain is calculated using the PSD value $[6,31]$. The spatial PSD of the road surface profile $S(\Omega)$ is generally described as a function of the spatial frequency $\Omega /$ cycle $^{-1}$. The spectral density of offroad terrain is thus written in accordance with ISO proposal [32] over different spatial frequency ranges as

$$
S(\Omega)=S\left(\Omega_{0}\right) \cdot\left(\frac{\Omega}{\Omega_{0}}\right)^{-w_{0}},
$$

where $w_{0}=3$ for $\Omega \leq \Omega_{0}$ and $w_{0}=2.25$ for $\Omega>\Omega_{0}$; the value $S\left(\Omega_{0}\right)$ provides a measure for the random terrain with the reference spatial frequency $\Omega_{0}=1 / 2 \pi$ cycle $\mathrm{m}^{-1}$.
TABLE 1: The parameters of the unpaved off-road classification.

\begin{tabular}{lcccc}
\hline Classification & Good & Medium & Poor & Very poor \\
\hline$w_{0}$ & 2.25 & 2.25 & 2.14 & 2.14 \\
$S\left(\Omega_{0}\right) \times 10^{-6} / \mathrm{m}^{3} \mathrm{cyc}^{-1}$ & 199.8 & 973.9 & 3782.5 & 102,416 \\
\hline
\end{tabular}

More specifically, assuming the vehicle travels with a forward speed $v_{0}$, the off-road terrain irregularities in the time domain can then be simulated by the series

$$
q(t)=\sum_{i=1}^{N} s_{i} \sin \left(i \Delta \omega t+\varphi_{i}\right)
$$

where $N$ is the number of intervals, $s_{i}=\sqrt{2 S(i \Delta n) \Delta n}$ is the amplitude of each excitation harmonic in which $S$ is the target spectral density, $\Delta n=2 \pi / L$, and $L$ is the length of road segment, $\varphi_{i}$ is a random phase uniformly distributed between 0 and $2 \pi$, and $\Delta \omega=\Delta n v_{0}$ is the fundamental temporal frequency. Mitschke [33] extended the spectral density ranges for the unpaved off-road classifications apart from the traditional asphalt road classifications, including the classification ranges from good to very poor, as listed in Table 1 and shown in Figure 6(b), and a desired terrain roughness can be yielded by choosing a value in the spectral density ranges.

In order to develop an off-road terrain roughness input for the vibratory roller close to the actual terrain condition, the simulation parameters used for generating the time domain of a poor terrain roughness, as shown in Figure 6(a), are $v_{0}=1.67 \mathrm{~m} \mathrm{~s}^{-1}, L=84 \mathrm{~m}, \Delta t=0.005 \mathrm{~s}, w_{0}=2.14$, and $S\left(\Omega_{0}\right)=3782.5 \times 10^{-6} \mathrm{~m}^{3}$ cycle $^{-1}$. The PSD of the offroad terrain irregularity obtained from the time domain is depicted in Figure 6(b). The frequency region of the input signal is mainly below $10 \mathrm{~Hz}$. 
TABLE 2: The reference parameters of a single drum vibratory roller.

\begin{tabular}{|c|c|}
\hline Parameter & Value \\
\hline$m_{s} / \mathrm{kg}$ & 85 \\
\hline$m_{c} / \mathrm{kg}$ & 891 \\
\hline$m_{\mathrm{ff}} / \mathrm{kg}$ & 2822 \\
\hline$m_{\mathrm{fr}} / \mathrm{kg}$ & 4464 \\
\hline$m_{d} / \mathrm{kg}$ & 4378 \\
\hline$I_{c x} / \mathrm{kgm}^{2}$ & 560 \\
\hline$I_{c y} / \mathrm{kgm}^{2}$ & 523 \\
\hline$I_{\mathrm{rf} x} / \mathrm{kgm}^{2}$ & $3.1 \times 10^{3}$ \\
\hline$I_{\mathrm{rf} y} / \mathrm{kgm}^{2}$ & $1.2 \times 10^{4}$ \\
\hline$I_{\mathrm{ff} x} / \mathrm{kgm}^{2}$ & $1.9 \times 10^{3}$ \\
\hline$I_{d x} / \mathrm{kgm}^{2}$ & $3.0 \times 10^{3}$ \\
\hline$b_{1} / \mathrm{m}$ & 0.55 \\
\hline$b_{2} / \mathrm{m}$ & 0.7 \\
\hline$b_{3} / \mathrm{m}$ & 0.68 \\
\hline$b_{4} / \mathrm{m}$ & 0.945 \\
\hline$b_{5} / \mathrm{m}$ & 0.945 \\
\hline$l_{1} / \mathrm{m}$ & 0.383 \\
\hline$l_{2} / \mathrm{m}$ & 0.1 \\
\hline$l_{3} / \mathrm{m}$ & 0.524 \\
\hline$l_{4} / \mathrm{m}$ & 0.136 \\
\hline$l_{5} / \mathrm{m}$ & 0.76 \\
\hline$l_{6} / \mathrm{m}$ & 0.9 \\
\hline$l_{7} / \mathrm{m}$ & 0.6 \\
\hline$l_{8} / \mathrm{m}$ & 1.5 \\
\hline$k_{s} / \mathrm{N} \mathrm{m}^{-1}$ & $1.2 \times 10^{4}$ \\
\hline$k_{d 1,2} / \mathrm{N} \mathrm{m}^{-1}$ & $3.9 \times 10^{6}$ \\
\hline$k_{t 1,2} / \mathrm{N} \mathrm{m}^{-1}$ & $0.5 \times 10^{6}$ \\
\hline$c_{s} / \mathrm{Ns} \mathrm{m}^{-1}$ & $1.2 \times 10^{2}$ \\
\hline$c_{d 1,2} / \mathrm{Ns} \mathrm{m}^{-1}$ & $2.9 \times 10^{3}$ \\
\hline$c_{t 1,2} / \mathrm{Ns} \mathrm{m}^{-1}$ & $4.0 \times 10^{3}$ \\
\hline$f / \mathrm{Hz}$ & $28 / 35$ \\
\hline$F_{0} / \mathrm{MN}$ & $0.28 / 0.19$ \\
\hline
\end{tabular}

\section{Results and Discussion}

The performance of three different cab's isolation mounts is evaluated under the interaction of wheels and off-road terrain in both time and frequency domain. The reference parameters of the vehicle are given in Table 2. In addition, for the lumped parameters of three cab's isolation mounts, as listed in Table 3, herein, the traditional rubber mounts and the main rubber of hydraulic mounts are the same stiffness $k_{r i}$ and damping constants $c_{r i}$ [21]. The static stiffness constants $k_{e i}$ of pneumatic mounts are also equivalently calculated with the above two isolation mounts. The vehicle ride comfort is the main goal for evaluation performance.

3.1. Evaluation Criteria. The performance of the vehicle suspension system was evaluated by three main indices in the time domain, including the ride comfort, working space, and road holding characteristics. Among these three indices, the ride comfort performance evaluated via the weighted RMS acceleration response was considered to be the most important index [21]. In addition, in the international standard ISO 2631-1 [34], the acceleration PSD response was also applied to estimate the effect of vibration on the endurance limit of the human body in the frequency domain. It was suggested that a low-frequency range of $4-10 \mathrm{~Hz}$ for the vertical and of $0.5-2 \mathrm{~Hz}$ for the rotational vibrations seriously affected the driver's health and safety.

In this study, the performance of three different cab's isolation mounts is evaluated through the acceleration PSD responses and the weighted RMS acceleration responses of the vertical driver's seat, cab's pitch, and roll vibrations in both the frequency and time domains. Thus, the smaller values of the acceleration PSD and the weighted RMS acceleration mean better ability of the corresponding isolation mounts. The expression of the weighted RMS acceleration response is defined by

$$
a_{w l}^{k}=\sqrt{\frac{1}{T} \int_{0}^{T}\left[a_{w l}^{k}(t)\right]^{2} d t},
$$

where superscript $k$ denotes $\mathrm{R}, \mathrm{H}$, or $\mathrm{P}$ of three cab's isolation mounts, respectively, subscript $l$ refers to the vertical driver's seat $\left(z_{s}\right)$, cab's pitch $\left(\phi_{c}\right)$, or cab roll $\left(\theta_{c}\right)$ vibrations, $a_{w l}^{k}(t)$ is the acceleration response of $\mathrm{R}, \mathrm{H}$, or $\mathrm{P}$ in the $l$ as a function of time, and $T=50 \mathrm{~s}$ is the duration of the simulation.

3.2. Experiment Results. In this section, comparisons are used to validate the vibratory roller model with the cab rubber mounts and verify its accuracy through experiment investigations. The experiment was carried out under the same conditions of the dynamic simulation when the vehicle moves and compacts an elastic-plastic soil ground. Three steps in experiments were described as follows:

(i) Preparation step: instruments for the experiment including a single drum vibratory roller XS120, ICP ${ }^{\circledR}$ three-direction acceleration sensors, Belgium LMS dynamic test, and analysis system were used to measure the vibration accelerations. The sensors were calibrated and installed on the driver's seat and the cab floor at four locations of isolation mounts. The arrangement of measuring points and instrumentations is shown in Figure 7.

(ii) Measurement step: the multipoint measurement method for the vehicle ride comfort was applied for analysis and comparison. The process of measurement was performed under four different conditions such as at low/high excitation frequency $28 / 35 \mathrm{~Hz}$ of the rigid drum when the vehicle compacted an original place and when the vehicle moved and compacted on an elastic-plastic soil ground at $0.83 \mathrm{~m} \mathrm{~s}^{-1}$ forward speed.

(iii) Data extraction step: the data measurements were carried out including the vertical acceleration on the driver's seat and the vertical accelerations at four measurement points on the cab floor.

The acceleration responses of cab's pitch and roll angles were derived from the measured vertical accelerations at four measurement points on the cab floor by using kinematic 
TABLE 3: The lumped parameters of rubber $(\mathrm{R})$, hydraulic $(\mathrm{H})$, and pneumatic $(\mathrm{P})$ mounts.

\begin{tabular}{lccccccc}
\hline Parameter & \multicolumn{3}{c}{$\mathrm{R}$ and $\mathrm{H}$} \\
& $k_{r i} / \mathrm{N} \mathrm{m}^{-1}$ & $c_{r i} / \mathrm{Ns} \mathrm{m}^{-1}$ & $c_{f i} / \mathrm{Ns}^{2} \mathrm{~m}^{-2}$ & $k_{e i} / \mathrm{N} \mathrm{m}^{-1}$ & $k_{v i} / \mathrm{N} \mathrm{m}^{-1}$ & $M_{i} / \mathrm{kg}^{5}$ & $c_{\beta i} / \mathrm{Ns}^{2} \mathrm{~m}^{-2}$ \\
\hline Font-end mount & $9.1 \times 10^{5}$ & 218 & $20 \times 10^{3}$ & $9.1 \times 10^{5}$ & $15.3 \times 10^{5}$ & 98 & $12.4 \times 10^{3}$ \\
Rear-end mount & $1.2 \times 10^{5}$ & 29 & $4.5 \times 10^{3}$ & $1.2 \times 10^{5}$ & $2.01 \times 10^{5}$ & 33 & $10.7 \times 10^{3}$ \\
\hline
\end{tabular}

TABLE 4: The lumped parameters of the Grenville loam.

\begin{tabular}{|c|c|c|c|c|c|c|}
\hline Terrain type & Moisture content $/ \%$ & $n$ & $k_{c} / \mathrm{N} \mathrm{m}^{-(n+1)}$ & $k_{\varphi} / \mathrm{N} \mathrm{m}^{-(n+2)}$ & $c / \mathrm{Pa}$ & $\varphi /^{\circ}$ \\
\hline Grenville loam & 24 & 1.01 & $0.06 \times 10^{3}$ & $5880 \times 10^{3}$ & $3.1 \times 10^{3}$ & 29.8 \\
\hline
\end{tabular}

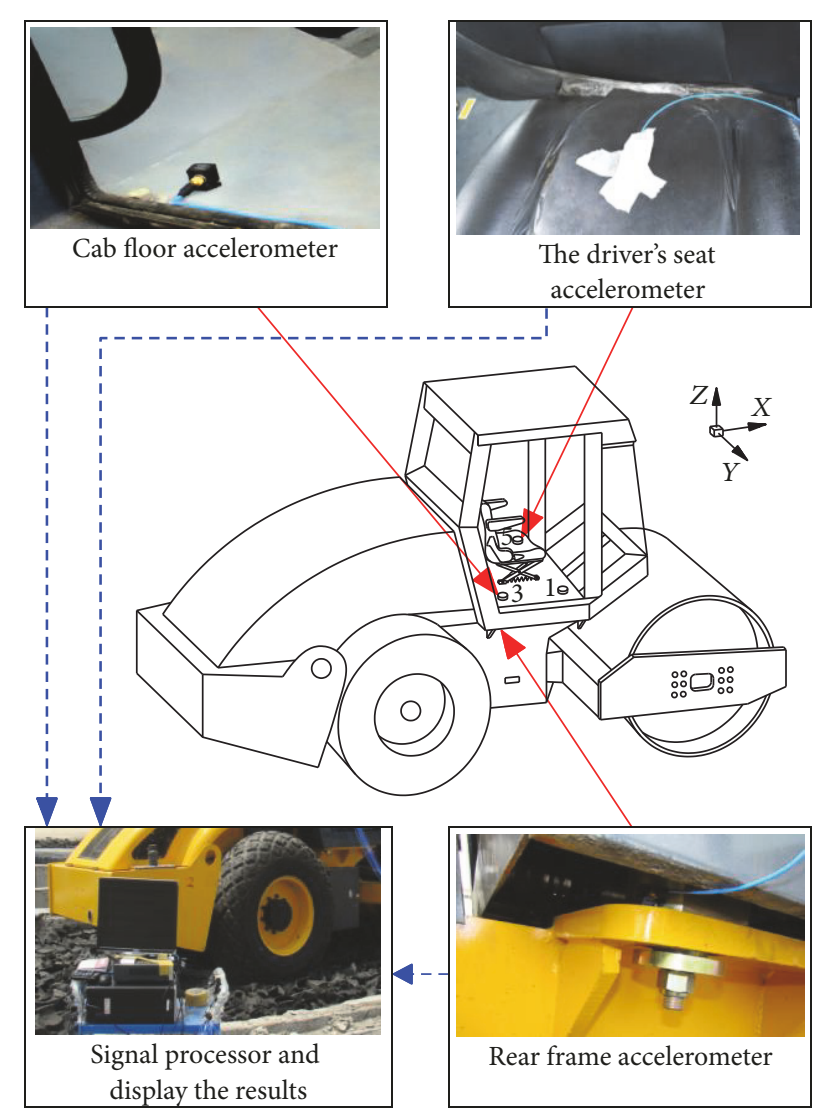

Figure 7: Diagrammatic sketch of the experimental setup.

relations of the cab. Assuming small angular motions and negligible contribution due to structure flexibility, thus, the acceleration responses of cab's pitch and roll angles are calculated by

$$
\begin{aligned}
& \ddot{\phi}_{c}=\frac{\ddot{z}_{c 2}-\ddot{z}_{c 4}}{l_{c}}, \\
& \ddot{\theta}_{c}=\frac{\ddot{z}_{c 1}-\ddot{z}_{c 2}}{b_{c}},
\end{aligned}
$$

where $\ddot{z}_{c i}(i=1-4)$ are the vertical accelerations at four measurement points on the cab floor and $l_{c}$ and $b_{c}$ are the distance between measurement points.

The acceleration PSD responses and the weighted RMS acceleration responses of the vertical driver's seat, cab's pitch, and roll vibrations are compared with the experimental results under the same condition of a low excitation frequency $28 \mathrm{~Hz}$ of the drum when the vehicle moves and compacts the elastic-plastic soil ground at $0.83 \mathrm{~m} \mathrm{~s}^{-1}$ forward speed, as shown in Figures 8 and 9.

As plotted in Figure 8, comparison between simulation and experimental results shows that the simulation results almost agree with the tests regarding the frequency of the various peaks in the responses and the trend. Besides, the simulation results of the weighted RMS acceleration responses of the vertical driver's seat, cab's pitch, and roll vibrations also are a small deviation of $10.13 \%, 11.36 \%$, and $12.67 \%$ in comparison with their measured results, as shown in Figure 9. It implies that the mathematical model of the vibratory roller is accurate and feasible for low-frequency vibration performances analysis of cab's isolation mounts.

3.3. Ride Comfort Analysis When the Vehicle Travels on the Deformable Terrain. The five types of soft terrain from LETE sand to Grenville loam had been given by Wong [35] through the data of field measurement. In this study, the vehicle is assumed to be travelling on a terrain type of Grenville loam at $1.67 \mathrm{~m} \mathrm{~s}^{-1}$ forward speed. The Grenville loam's parameters in Table 4 and its off-road terrain in Figures 6(a) and 6(b) are the random excitation inputs. Simulations are then carried out to compare the performances of three cab's isolation mounts.

3.3.1. Frequency Acceleration Responses. The simulation results of the acceleration PSD responses of the vertical driver's seat, cab's pitch, and roll vibrations with three cab's isolation mounts are plotted in Figure 10. The peaks of acceleration PSD responses of vertical driver's seat and cab's pitch vibrations shown in Figures 10(a) and 10(b) exhibit that the resonance frequencies occur at $0.79,1.79,2.09,2.49$, and $8.39 \mathrm{~Hz}$ with both traditional rubber mounts and hydraulic mounts and at $0.89,1.8,2.2,2.6$, and $8.39 \mathrm{~Hz}$ with pneumatic 


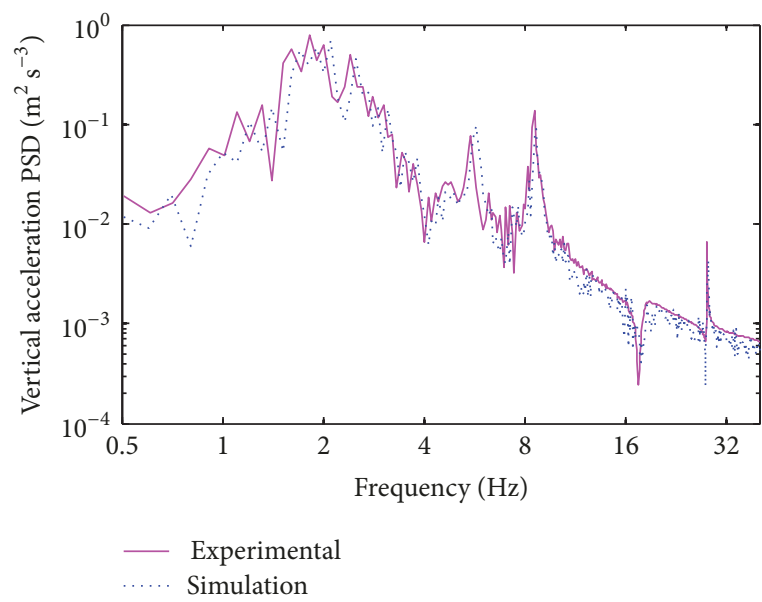

(a) Vertical driver's seat

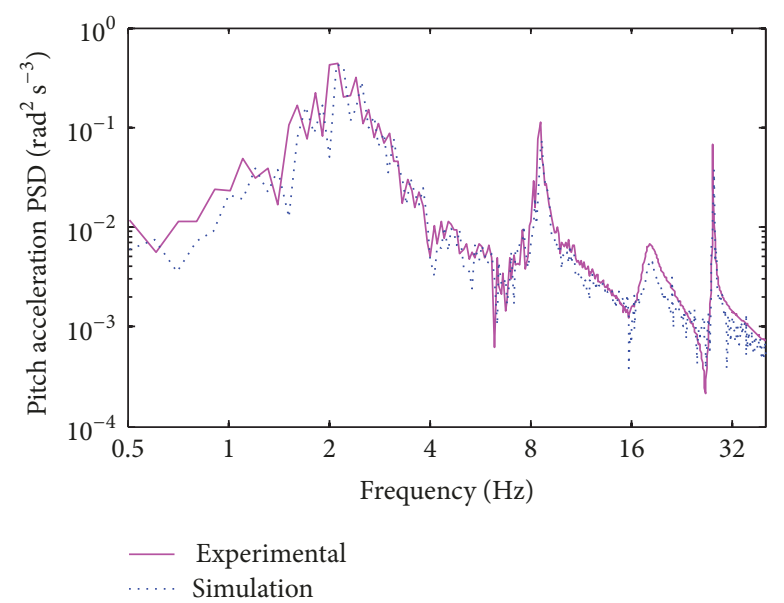

(b) Cab's pitch angle

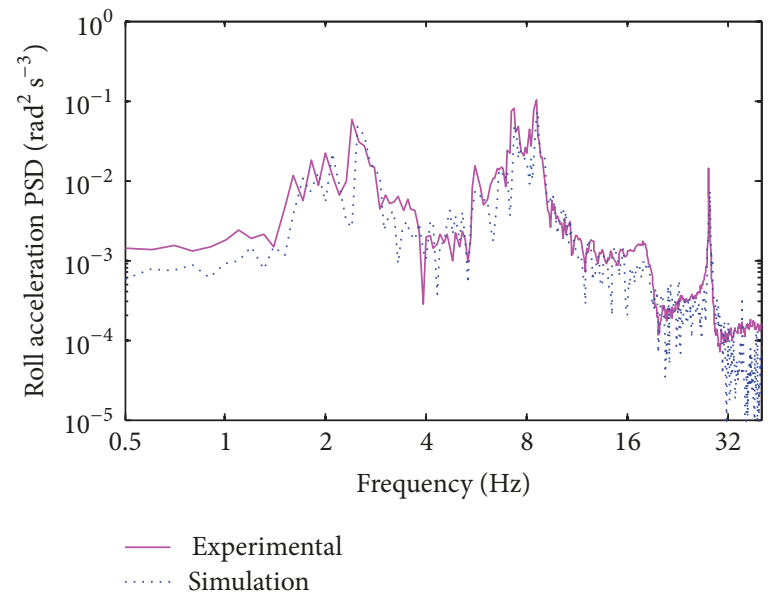

(c) Cab's roll angle

FIgURE 8: The acceleration PSD responses under a low excitation frequency $28 \mathrm{~Hz}$ of the drum.

mounts. Meanwhile, the resonance peaks of acceleration PSD responses of cab's roll angle shown in Figure 10(c) occur at $2.09,2.59$, and $8.39 \mathrm{~Hz}$ with both rubber mounts and hydraulic mounts and at 2.6 and $8.39 \mathrm{~Hz}$ with pneumatic mounts. Particularly, the results show that hydraulic mounts with the nonlinear damping characteristics have almost no effect on the resonance frequencies in comparison with traditional rubber mounts, which had been proved by Sun and Zhang [21]. However, at low-frequency range from 0.79 to $2.6 \mathrm{~Hz}$, the resonance frequencies with pneumatic mounts are higher in comparison with both traditional rubber and hydraulic mounts in all three directions. This can be due to the influence of the elastic stiffness of air bags which may be changed and depended on the pressure, volume, mass, and density of the air in air bags.

Also at a low-frequency range of $0.79-2.6 \mathrm{~Hz}$, the results specifically emphasize that traditional rubber mounts show more resonance frequencies than those on the off-road terrain in comparison with those on the rigid road which only show a resonance frequency near $2.1 \mathrm{~Hz}$ [7] or near $2.77 \mathrm{~Hz}$ [21]. It implies that the driver's ride comfort is strongly influenced by an off-road deformable terrain in low-frequency region. Consequently, the maximum values of acceleration PSD responses with three cab's isolation mounts at $0.79-2.6 \mathrm{~Hz}$ are given to compare the performances of three cab's isolation mounts.

The maximum PSD values with three cab's isolation mounts are listed in Table 5. The maximum PSD values of the vertical driver's seat, cab's pitch, and roll vibrations with hydraulic mounts are strongly reduced by $55.28 \%, 57.65 \%$, and $35.16 \%$ compared with traditional rubber mounts. Meanwhile, with pneumatic mounts, the maximum PSD values of the vertical driver's seat and cab's pitch vibrations are also lower by $39.02 \%$ and $32.94 \%$; however, those of cab's roll vibration are higher by $7.14 \%$ in comparison with traditional rubber mounts.

Besides, at the frequency range above $10 \mathrm{~Hz}$, Figure 10 shows that the acceleration PSD responses with hydraulic mounts are all clearly lower in comparison with traditional rubber mounts whereas their values with pneumatic mounts are all higher compared with traditional rubber mounts in all three directions. It can be seen from the above analysis that 
TABLE 5: The maximum PSDs of the acceleration responses with three cab's isolation mounts.

\begin{tabular}{|c|c|c|c|c|c|}
\hline \multirow{2}{*}{ Parameters } & \multirow{2}{*}{$f / \mathrm{Hz}$} & \multicolumn{2}{|c|}{ Maximum PSD } & \multirow{2}{*}{$f / \mathrm{Hz}$} & \multirow{2}{*}{$\begin{array}{c}\text { Maximum PSD } \\
\mathrm{P}\end{array}$} \\
\hline & & $\mathrm{R}$ & $\mathrm{H}$ & & \\
\hline Vertical vibration $/ \mathrm{m}^{2} \mathrm{~s}^{-3}$ & 2.09 & 1.23 & 0.55 & 2.6 & 0.75 \\
\hline Pitch vibration $/ \mathrm{rad}^{2} \mathrm{~s}^{-3}$ & 2.09 & 0.85 & 0.36 & 2.6 & 0.57 \\
\hline Roll vibration $/ \mathrm{rad}^{2} \mathrm{~s}^{-3}$ & 2.59 & 0.091 & 0.059 & 2.6 & 0.098 \\
\hline
\end{tabular}

TABLE 6: The parameters of an elastoplastic ground deformation with a high density soil.

\begin{tabular}{|c|c|c|c|c|}
\hline Road ground & $\varepsilon$ & $k_{\mathrm{sp}} / \mathrm{N} \mathrm{m}^{-1}$ & $k_{\mathrm{se}} / \mathrm{N} \mathrm{m}^{-1}$ & $c_{\mathrm{se}} / \mathrm{Ns} \mathrm{m}^{-1}$ \\
\hline Elastoplastic soil & 0.87 & $283 \times 10^{6}$ & $42.3 \times 10^{6}$ & $37.1 \times 10^{3}$ \\
\hline
\end{tabular}

TABLE 7: The resonance frequencies of three cab's isolation mounts.

\begin{tabular}{|c|c|c|c|c|c|c|c|c|c|c|c|c|}
\hline \multirow{2}{*}{ Isolation mounts } & \multicolumn{6}{|c|}{ Low excitation frequency, $28 \mathrm{~Hz}$, of the drum } & \multicolumn{6}{|c|}{ High excitation frequency, $35 \mathrm{~Hz}$, of the drum } \\
\hline & $f_{1}$ & $f_{2}$ & $f_{3}$ & $f_{4}$ & $f_{5}$ & $f_{6}$ & $f_{1}$ & $f_{2}$ & $f_{3}$ & $f_{4}$ & $f_{5}$ & $f_{6}$ \\
\hline $\mathrm{R}$ and $\mathrm{H}$ & 1.69 & 1.89 & 2.09 & 2.49 & 5.69 & 8.59 & 1.69 & 1.89 & 2.09 & 2.49 & 5.69 & 8.59 \\
\hline $\mathrm{P}$ & 1.8 & 2.2 & 2.6 & 5.2 & 6.5 & & 1.8 & 2.2 & 2.6 & 5.69 & 6.79 & \\
\hline
\end{tabular}

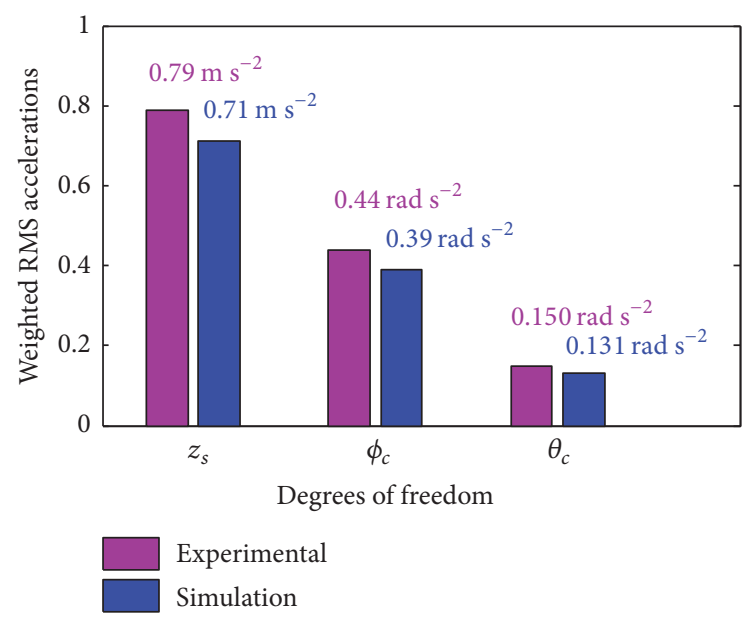

FIGURE 9: The weighted RMS acceleration responses under a low excitation frequency $28 \mathrm{~Hz}$ of the drum.

the improved driver's health and safety with hydraulic mounts are especially evident in comparison with both the pneumatic and traditional rubber mounts in the low-frequency range.

3.3.2. The Weighted RMS Acceleration Responses. The results of the weighted RMS acceleration responses of the vertical driver's seat, cab's pitch, and roll vibrations with three different isolation mounts are shown in Figure 11. With traditional rubber mounts, the weighted RMS values of the vertical driver's seat and cab's pitch vibrations are quite great, which can make the driver tired and uncomfortable [34]; however, those of cab's roll vibration are relatively small, and these results are similarly the basis of measurements and simulations results by Kordestani et al. and Quynh [12, 17]. In addition, the weighted RMS values of the vertical driver's seat, cab's pitch, and roll vibrations with hydraulic mounts are, respectively, decreased by $32.48 \%, 26.31 \%$, and $63.03 \%$ in comparison with traditional rubber mounts and by $13.11 \%$,
$16.24 \%$, and $1.42 \%$ in comparison with pneumatic mounts. Thus, the driver's ride comfort can be clearly improved by using the hydraulic mounts.

3.4. Ride Comfort Analysis When Vehicle Compacts the Elastoplastic Soil Ground. The soil properties are changed during the interaction between wheels and soil ground. In the initial phase, the soil is relatively soft; thus, a continuous contact between the drum and soil can exist. The soil density then becomes higher after the repeated phase of the drum. And in the final phase, the drum-soil contact could be broken due to the interaction of the drum with the high-density soil (elastoplastic soil). The elastoplastic soil properties are represented by three different values of the plasticity parameter $\varepsilon$, including a low density soil $\varepsilon=0.34$, medium density soil $\varepsilon=0.72$, and high-density soil $\varepsilon=0.87$ [2]. However, the property of a low density soil $(\varepsilon=0.34)$ is similar to the property of a soft soil deformation which is simulated in Section 3.3. Thus, an elastoplastic soil concerned with a medium- or high-density soil is chosen in this part.

In the compaction condition, the vibratory roller invariably moves at very slow speed on the terrain deformation. Thus, the vehicle forward speed at $0.83 \mathrm{~m} \mathrm{~s}^{-1}$ and an excitation frequency of $28 / 35 \mathrm{~Hz}$ of the drum on a high-density soil ground with parameters listed in Table 6 are chosen as the input parameters of the model in Figure 5. Meanwhile, the elastic tyres are assumed to be moving on a soil deformation of the model in Figure 4(b). The vehicle model is then simulated to evaluate the performance of three cab's isolation mounts.

3.4.1. Frequency Acceleration Responses. The acceleration PSD responses with three cab's isolation mounts at a low/high excitation frequency $28 / 35 \mathrm{~Hz}$ of the drum are given in Figures 12 and 13 . The results of the resonance frequencies are also listed in Table 7. Similarly, in the vehicle travelling condition, the resonance peaks of the acceleration PSD 
TABLE 8: The maximum PSDs of the acceleration responses with three cab's isolation mounts.

\begin{tabular}{lccccccccccc}
\hline & \multicolumn{3}{c}{ Low excitation frequency, $28 \mathrm{~Hz}$, of the drum } & \multicolumn{4}{c}{ High excitation frequency, 35 Hz, of the drum } \\
Parameters & \multicolumn{3}{c}{ Maximum PSD } & $f / \mathrm{Hz}$ & Maximum PSD & $f / \mathrm{Hz}$ & Maximum PSD & $f / \mathrm{Hz}$ & Maximum PSD \\
& & $\mathrm{R}$ & $\mathrm{H}$ & & $\mathrm{P}$ & & $\mathrm{R}$ & $\mathrm{H}$ & & $\mathrm{P}$ \\
\hline Vertical vibration $/ \mathrm{m}^{2} \mathrm{~s}^{-3}$ & 2.09 & 0.68 & 0.37 & 1.8 & 0.65 & 2.09 & 0.54 & 0.32 & 1.8 & 0.51 \\
Pitch vibration $/ \mathrm{rdd}^{2} \mathrm{~s}^{-3}$ & 2.09 & 0.42 & 0.19 & 1.8 & 0.48 & 2.09 & 0.42 & 0.18 & 1.8 & 0.35 \\
Roll vibration $/ \mathrm{rad}^{2} \mathrm{~s}^{-3}$ & 2.49 & 0.048 & 0.032 & 2.2 & 0.042 & 2.49 & 0.054 & 0.026 & 5.69 & 0.041 \\
\hline
\end{tabular}

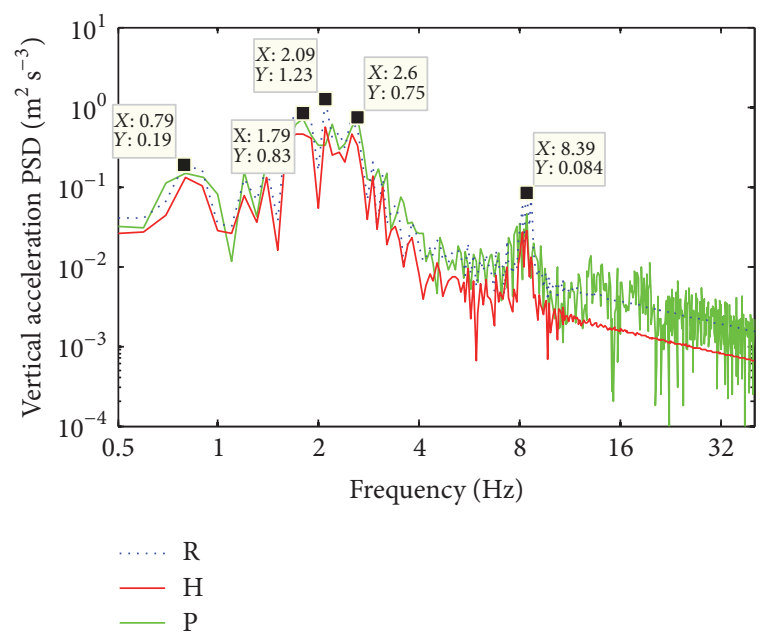

(a) Vertical driver's seat

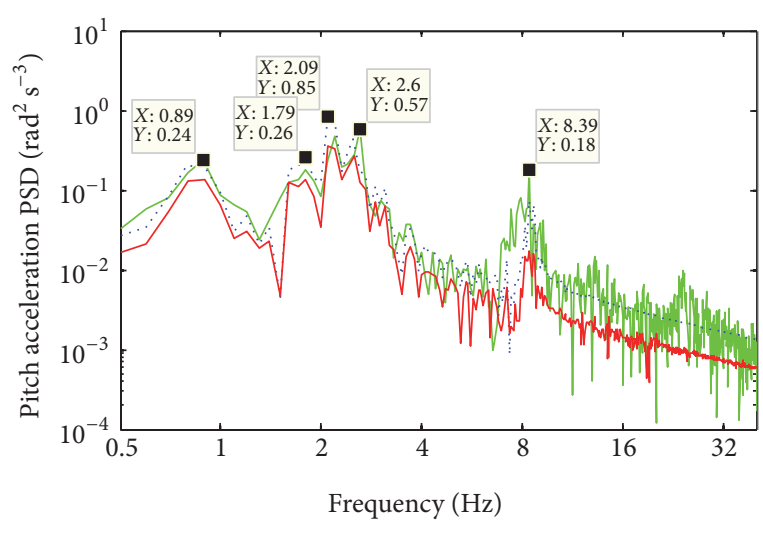

…. R

$-\mathrm{H}$

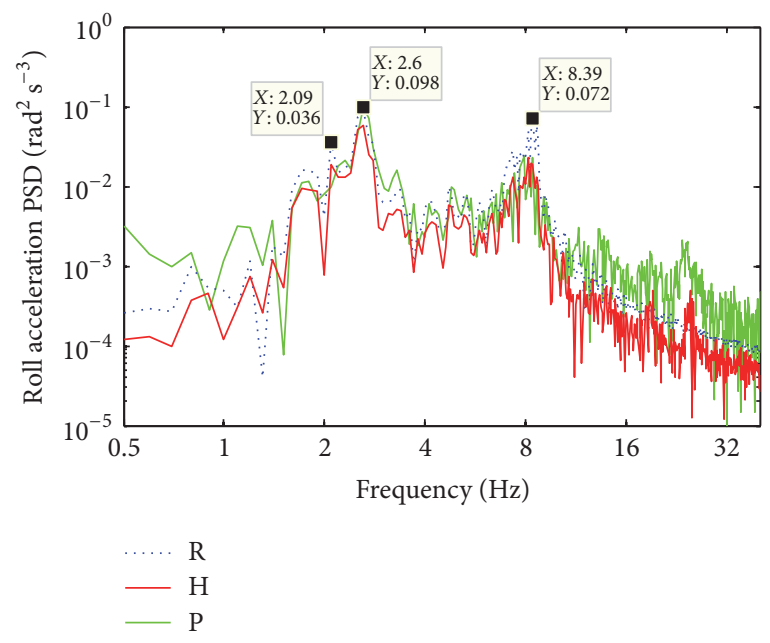

(c) Cab's roll angle

FIGURE 10: The acceleration PSD responses under an excitation of the off-road terrain of Grenville loam.

responses with hydraulic rubber mounts are not changed in comparison with traditional rubber mounts. Meanwhile, the resonance frequencies with pneumatic mounts are slightly higher in comparison with both traditional rubber and hydraulic mounts. Besides, at a low-frequency range of $1.69-2.49 \mathrm{~Hz}$, traditional rubber mounts also occur show resonance frequencies; thus, the ride comfort is strongly influenced by an elastoplastic soil ground in low-frequency region.

In order to compare the performances of three cab's isolation mounts, the maximum PSD values of three cab's isolation mounts are also carried out in Table 8. The maximum PSD values of the vertical driver's seat, cab's pitch, and roll vibrations with hydraulic mounts are strongly reduced by 


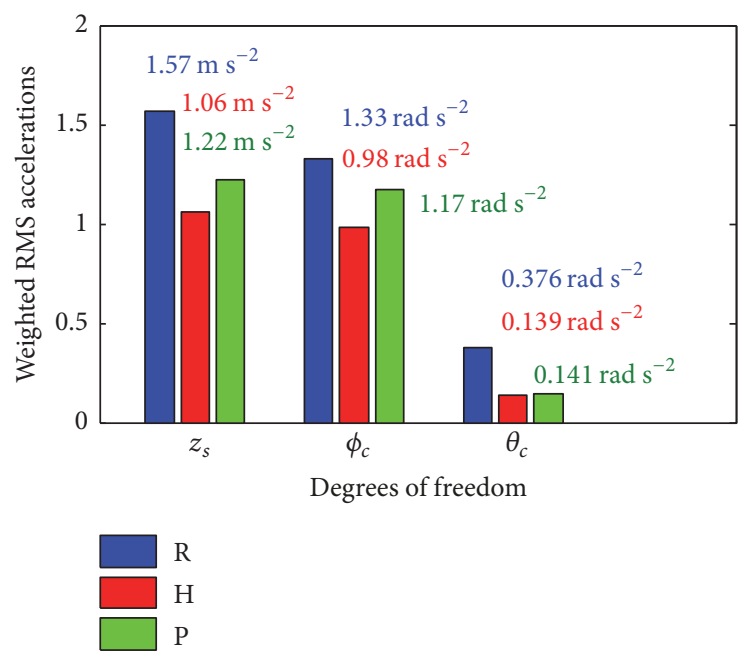

FIGURE 11: The weighted RMS acceleration responses under an excitation of the off-road terrain of Grenville loam.

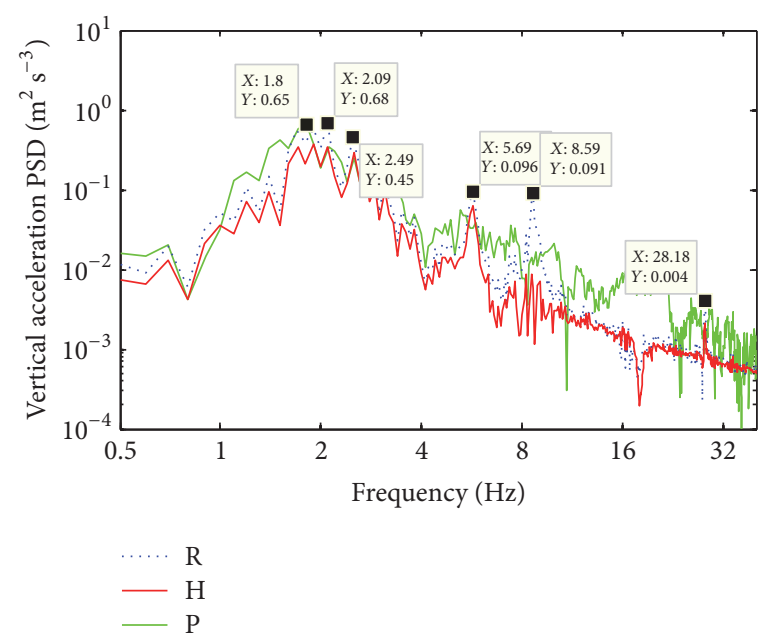

(a) Vertical driver's seat

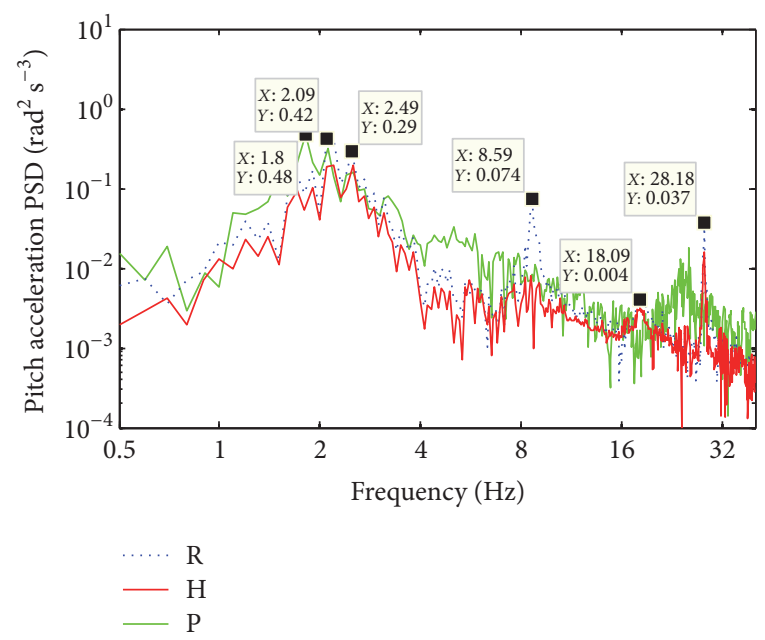

(b) Cab's pitch angle

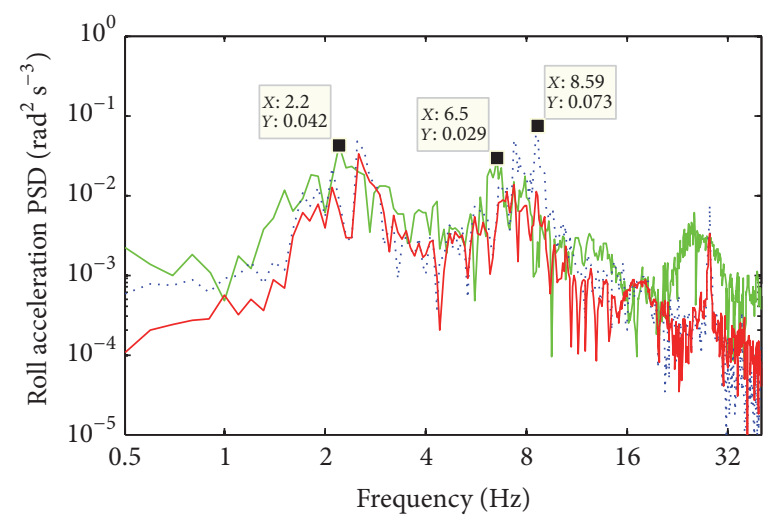

$\begin{array}{cc}\cdots & \mathrm{R} \\ -\mathrm{H} \\ \mathrm{P}\end{array}$

(c) Cab's roll angle

FIGURE 12: The acceleration PSD responses on a high-density soil ground at low excitation frequency $28 \mathrm{~Hz}$ of the drum. 


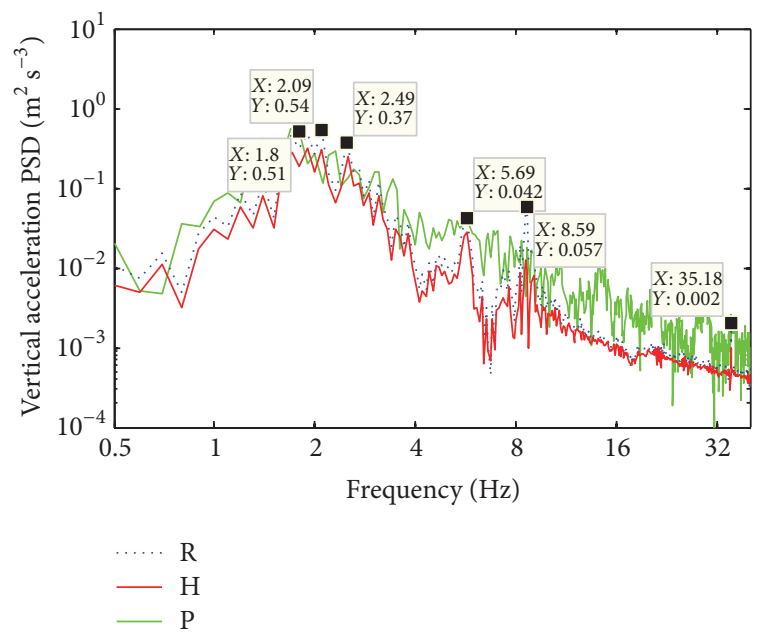

(a) Vertical driver's seat

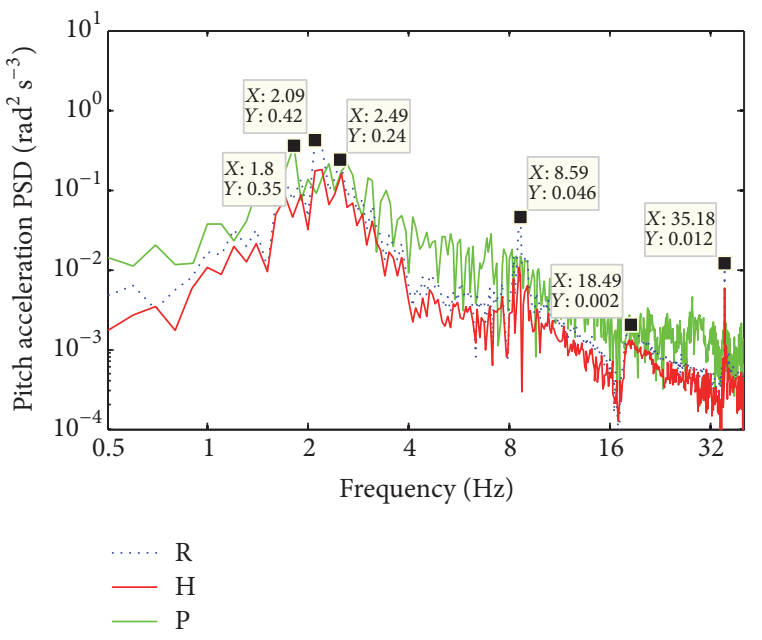

(b) Cab's pitch angle

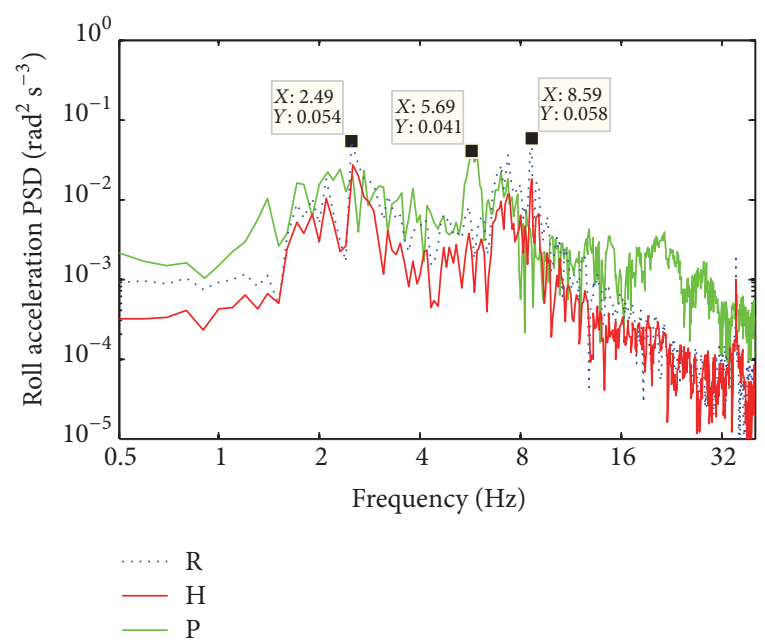

(c) Cab's roll angle

FIGURE 13: The acceleration PSD responses on a high-density soil ground at high excitation frequency $35 \mathrm{~Hz}$ of the drum.

$45.58 \%, 54.76 \%$, and $33.33 \%$ at a low excitation frequency $28 \mathrm{~Hz}$ and by $40.74 \%, 57.14 \%$, and $51.85 \%$ at a high excitation frequency, $35 \mathrm{~Hz}$, in comparison with traditional rubber mounts. Meanwhile, with pneumatic mounts, the maximum PSD values of the vertical driver's seat and cab's roll vibrations are also smaller by $4.41 \%$ and $12.50 \%$, and those of cab's pitch vibration are higher by $12.50 \%$ at a low excitation frequency $28 \mathrm{~Hz}$; however, all the maximum PSD values are, respectively, lower by $5.55 \%, 16.67 \%$, and $24.07 \%$ at a high excitation frequency, $35 \mathrm{~Hz}$, comparable with traditional rubber mounts.

At the frequency range above $10 \mathrm{~Hz}$, the resonance peaks of the acceleration PSD responses in Figures 12 and 13 show that the resonance frequencies with cab's isolation mounts also occur at $28.18 \mathrm{~Hz}$ or $35.18 \mathrm{~Hz}$ in all three directions. This can be due to the resonance of an excitation frequency $28 / 35 \mathrm{~Hz}$ of the vibratory drum. In addition, the resonance frequency of the acceleration PSD responses clearly appears at $18.49 \mathrm{~Hz}$ in both graphs of Figures 12 and 13 whereas this resonance frequency does not occur in the graph of
Figure 10, especially with traditional rubber mounts. This particularity may be due to the effect of the soil stiffness with the high-density soil ground. Besides, the results of the acceleration PSD responses with hydraulic mounts are all clearly lower whereas their values with pneumatic mounts are all strongly enhanced comparable with traditional rubber mounts in three directions, especially at a high excitation frequency $35 \mathrm{~Hz}$. Consequently, all the above analysis results also suggest that the driver's health and safety with hydraulic mounts are obviously improved in comparison with both the pneumatic and traditional rubber mounts on elastoplastic soil ground.

3.4.2. The Weighted RMS Acceleration Responses. Figure 14(a) shows that, at a low excitation frequency, $28 \mathrm{~Hz}$, of the drum, the weighted RMS values of the vertical driver's seat and cab's pitch vibrations with pneumatic mounts are enhanced by $4.05 \%$ and $4.88 \%$ in comparison with traditional rubber mounts. Thus, pneumatic mounts have a little effect 


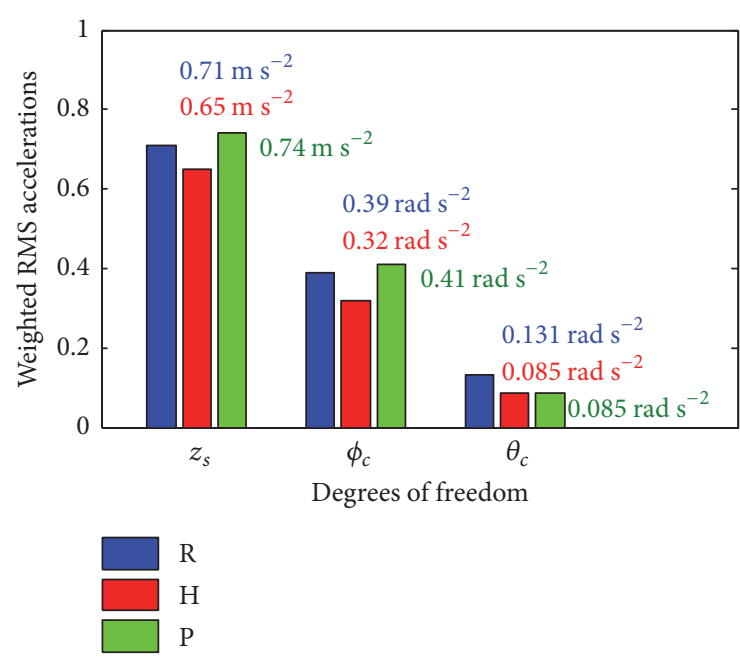

(a) Under a low excitation frequency, $28 \mathrm{~Hz}$, of the drum

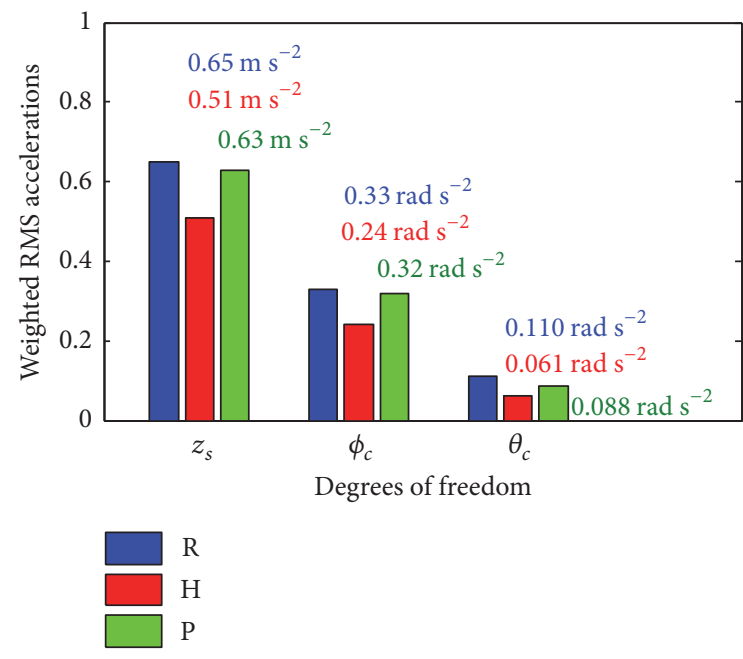

(b) Under a high excitation frequency, $35 \mathrm{~Hz}$, of the drum

FIGURE 14: The weighted RMS acceleration responses on a high-density soil ground.

on improving the driver's ride comfort. Meanwhile, with hydraulic mounts, their weighted RMS values are all, respectively, smaller by $8.45 \%, 17.95 \%$, and $35.11 \%$ compared with traditional rubber mounts. Therefore, the driver's ride comfort is clearly improved by using hydraulic mounts.

Besides, Figure 14(b) also shows that, at a high excitation frequency, $35 \mathrm{~Hz}$, the weighted RMS values of the vertical driver's seat and cab's pitch vibrations with pneumatic mounts are slightly reduced by $3.07 \%$ and $3.03 \%$ in comparison with traditional rubber mounts. Contrary to that with pneumatic mounts, their weighted RMS values with hydraulic mounts are all strongly decreased by $21.53 \%, 27.27 \%$, and $45.54 \%$ compared with traditional rubber mounts.

In addition, the driver's ride comfort is also significantly influenced by the excitation frequencies of the vibratory drum. As shown in Figures 14(a) and 14(b), the weighted RMS acceleration responses of the vertical driver's seat, cab's pitch, and roll vibrations at a high excitation frequency, $35 \mathrm{~Hz}$, comparable with a low excitation frequency, $28 \mathrm{~Hz}$, are all, respectively, lower by $8.45 \%, 15.38 \%$, and $16.03 \%$ with traditional rubber mounts, by $14.86 \%, 21.95 \%$, and $-3.41 \%$ with pneumatic mounts, and by $21.54 \%, 25 \%$, and $28.23 \%$ with hydraulic mounts. Therefore, all the above analysis results show that the driver's ride comfort can be improved clearly with hydraulic mounts when the vehicle moves and compacts an elastoplastic soil ground in low-frequency region.

\section{Conclusions}

Modeling and low-frequency performance analysis of an off-road vibratory roller equipped with three different cab's isolation mounts are addressed in this work. The performance of three cab's isolation mounts is evaluated through the acceleration PSD responses and the weighted RMS acceleration responses of the vertical driver's seat, cab's pitch, and the roll vibrations in both the frequency and the time domains.
The results show that the maximum PSD values of the vertical driver's seat, cab's pitch, and roll vibrations with the hydraulic mounts are strongly reduced by $55.28 \%, 57.65 \%$, and $35.16 \%$ compared with traditional rubber mounts. Besides, the weighted RMS values of the vertical driver's seat, cab's pitch, and roll vibrations with hydraulic mounts are also, respectively, lower by $13.11 \%, 16.24 \%$, and $1.42 \%$ in comparison with pneumatic mounts when the vehicle travels on a deformable terrain.

When the vehicle moves and compacts an elastoplastic soil ground, with hydraulic mounts, the weighted RMS values of the vertical driver's seat, cab's pitch, and roll vibrations are greatly decreased by $8.45 \%, 17.95 \%$, and $35.11 \%$ at a low excitation frequency, $28 \mathrm{~Hz}$, of the drum, and their maximum PSD values are strongly reduced by $45.58 \%, 54.76 \%$, and $33.33 \%$ at a low excitation frequency, $28 \mathrm{~Hz}$ and by $40.74 \%$, $57.14 \%$, and $51.85 \%$ at a high excitation frequency, $35 \mathrm{~Hz}$, comparable with the traditional rubber mounts.

\section{Conflicts of Interest}

The authors declare that there are no conflicts of interest regarding the publication of this paper.

\section{Acknowledgments}

This study is supported by the Science and Technology Support Program of Jiangsu, China (no. BE2014133) and the Prospective Joint Research Program of Jiangsu, China (no. BY2014127-01).

\section{References}

[1] D. Pietzsch and W. Poppy, "Simulation of soil compaction with vibratory rollers," Journal of Terramechanics, vol. 29, no. 6, pp. 585-597, 1992. 
[2] D. Adam and F. Kopf, "Theoretical analysis of dynamically loaded soils," in Proceedings of the European Workshop Compaction of Soils and Granular Materials, pp. 207-220, Paris, France, 2000.

[3] R. Anderegg and K. Kaufmann, "Intelligent compaction with vibratory rollers feedback control systems in automatic compaction and compaction control," Transportation Research Record, no. 1868, pp. 124-134, 2004.

[4] K. Tateyama, S. Ashida, R. Fukagawa, and H. Takahashi, "Geomechatronics - Interaction between ground and construction machinery and its application to construction robotics," Journal of Terramechanics, vol. 43, no. 3, pp. 341-353, 2006.

[5] M. Bekker, Introduction to Terrain-Vehicle Systems, University of Michigan Press, Ann Arbor, Mich, USA, 1969.

[6] J. Wong, Theory of Ground Vehicles, John Wiley \& Sons, New York, NY, USA, 2001.

[7] X. Zhang, Modelling, simulation and optimization of ride comfort for off road articulated dump trucks [Ph.D. thesis], Southeast University, 2010.

[8] A. Pakowski and D. Cao, "Effect of soil deformability on off-road vehicle ride dynamics," SAE International Journal of Commercial Vehicles, vol. 6, no. 2, pp. 362-371, 2013.

[9] C. Harnisch, B. Lach, R. Jakobs, M. Troulis, and O. Nehls, "A new tyre-soil interaction model for vehicle simulation on deformable ground," Vehicle System Dynamics, vol. 43, pp. 384394, 2005.

[10] R. A. Irani, R. J. Bauer, and A. Warkentin, "Dynamic wheelsoil model for lightweight mobile robots with smooth wheels," Journal of Intelligent \& Robotic Systems, vol. 71, no. 2, pp. 179193, 2013.

[11] S. Park, A. A. Popov, and D. J. Cole, "Influence of soil deformation on off-road heavy vehicle suspension vibration," Journal of Terramechanics, vol. 41, no. 1, pp. 41-68, 2004.

[12] A. Kordestani, S. Rakheja, P. Marcotte, A. Pazooki, and D. Juras, "Analysis of ride vibration environment of soil compactors," SAE International Journal of Commercial Vehicles, vol. 3, no. 1, pp. 259-272, 2010.

[13] R. V. Rinehart and M. A. Mooney, "Instrumentation of a roller compactor to monitor vibration behavior during earthwork compaction," Automation in Construction, vol. 17, no. 2, pp. 144150, 2008.

[14] J. Li, Z. Zhang, H. Xu, and Z. Feng, "Dynamic characteristics of the vibratory roller test-bed vibration isolation system: Simulation and experiment," Journal of Terramechanics, vol. 56, pp. 139-156, 2014.

[15] M. Griffin, Handbook of Human Vibration, Academic Press, London, UK, 1990.

[16] J. De Temmerman, K. Deprez, I. Hostens, J. Anthonis, and H. Ramon, "Conceptual cab suspension system for a self-propelled agricultural machine - part 2: operator comfort optimisation," Biosystems Engineering, vol. 90, no. 3, pp. 271-278, 2005.

[17] V. Quynh, Vibration study and control for cab of vibratory roller [Ph.D. thesis], Southeast University, 2013.

[18] P. Lee, J. Vogt, and S. Han, "Application of hydraulic body mounts to reduce the freeway hop shake of pickup trucks," SAE Technical Papers 2009-01-2126, 2009.

[19] T. Higuchi and K. Miyaki, "Work machine with operators cabin,” Tech. Rep., 1999, U.S. Patent No. 5984036.

[20] S. Jiao, Y. Wang, L. Zhang, and H. Hua, "Shock wave characteristics of a hydraulic damper for shock test machine," Mechanical Systems and Signal Processing, vol. 24, no. 5, pp. 1570-1578, 2010.
[21] X. Sun and J. Zhang, "Performance of earth-moving machinery cab with hydraulic mounts in low frequency," Journal of Vibration and Control, vol. 20, no. 5, pp. 724-735, 2014.

[22] P. Sundvall, "Comparisons between predicted and measured ride comfort in trains-a case study on modeling," TRITAFKT Report, Division of Railway Technology, Department of Vehicle Engineering, Royal Institute of Technology, Stockholm, Sweden, 2001.

[23] M. Presthus, Derivation of air spring model parameters for train simulation [M.S. thesis], Lulea University of Technology, 2002.

[24] H. J. Abid, J. Chen, and A. A. Nassar, "Equivalent air spring suspension model for quarter-passive model of passenger vehicles," International Scholarly Research Notices, vol. 2015, Article ID 974020, pp. 1-6, 2015.

[25] I. Hostens, K. Deprez, and H. Ramon, "An improved design of air suspension for seats of mobile agricultural machines," Journal of Sound and Vibration, vol. 276, no. 1-2, pp. 141-156, 2004.

[26] J. Yan, Z. Yin, X. Guo, and C. Fu, "Fuzzy control of semi-active air suspension for cab based on genetic algorithms," SAE Technical Papers 2008-01-2681, 2008.

[27] G. Tang, H. Zhu, Y. Zhang, and Y. Sun, "Studies of air spring mathematical model and its performance in cab suspension system of commercial vehicle," SAE Technical Papers, vol. 2015, no. 4, pp. 341-348, 2015.

[28] C. Harris and A. Piersol, Harris' Shock and Vibration Handbook, McGraw-Hill, New York, NY, USA, 5th edition, 2002.

[29] T. Ushijima and T. Dan, "Nonlinear B.B.A. for predicting vibration of vehicle with hydraulic engine mount," SAE Technical Papers 860550, 1986.

[30] M. Berg, "A three-dimensional air spring model with friction and orifice damping," in Proceedings of the 16th IAVSD Symposium, The Dynamics of Vehicles on Roads And on Tracks, vol. 33, pp. 528-539, Pretoria, South Africa, 1999.

[31] J. D. Robson, "Road surface description and vehicle response," International Journal of Vehicle Design, vol. 1, no. 1, pp. 25-35, 1979.

[32] International Organization for Standardization, "Reporting vehicle road surface irregularities," Tech. Rep. ISO/TC108/SC2/ WG4 N57, Thieme Medical Publishers, Stuttgart, Germany, 1982.

[33] M. Mitschke, Dynamik der Kraftfahrzeuge, Springer-Verlag, Berlin, Germany, 1972.

[34] International Organization for Standardization, "Mechanical vibration and shock-evaluation of human exposure to whole body vibration-part 2: General requi," Tech. Rep. ISO 26311:1997, ISO, Geneva, Switzerland, 1997.

[35] J. Y. Wong, "Data processing methodology in the characterization of the mechanical properties of terrain," Journal of Terramechanics, vol. 17, no. 1, pp. 13-41, 1980. 


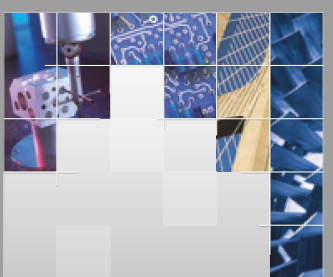

\section{Enfincering}
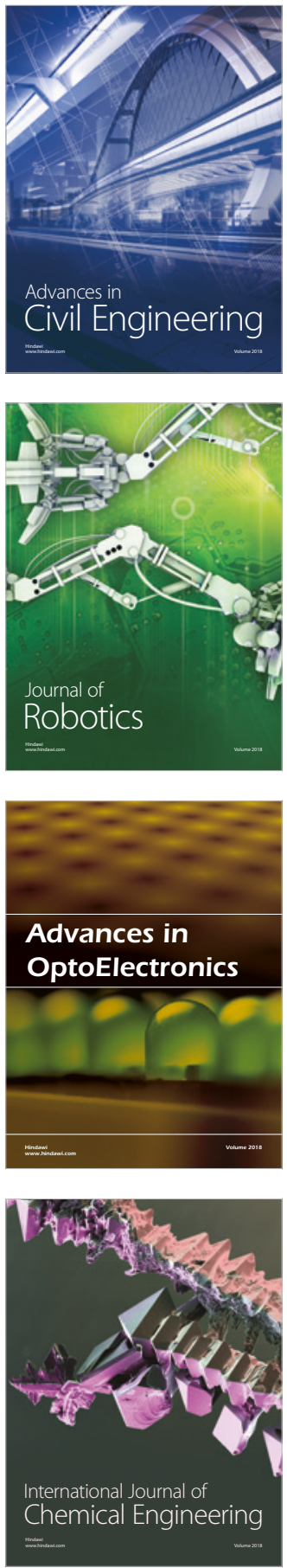

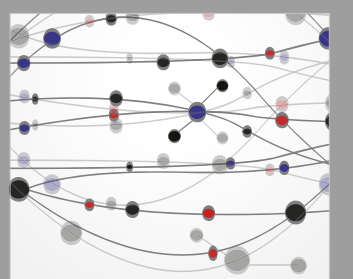

\section{Rotating \\ Machinery}

The Scientific World Journal

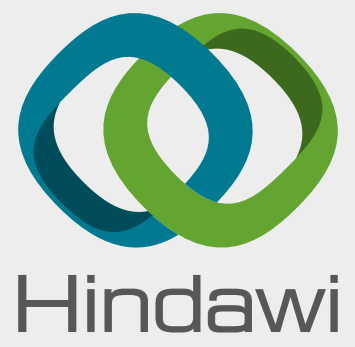

Submit your manuscripts at

www.hindawi.com
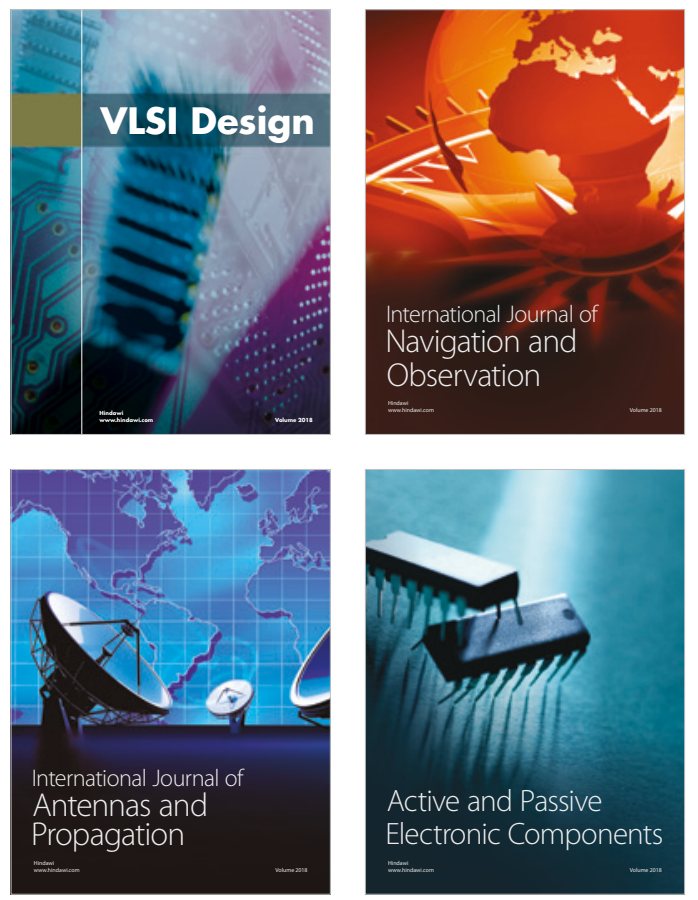
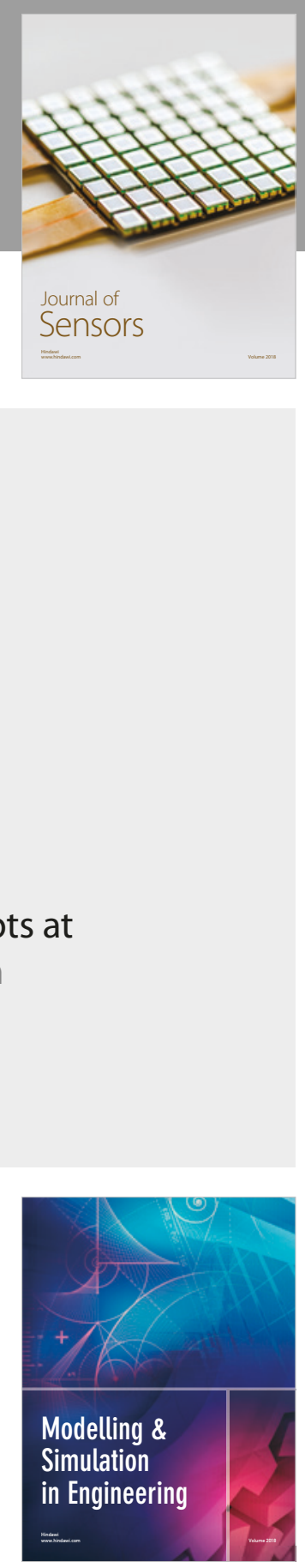

\section{Advances \\ Multimedia}
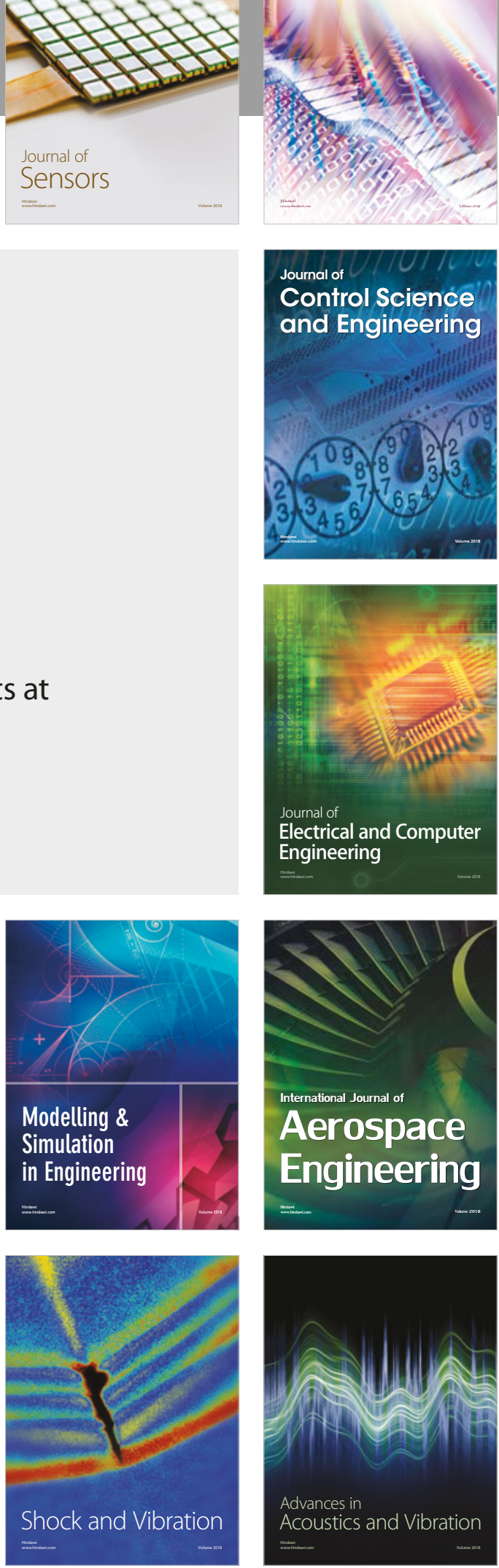